Portland State University

PDXScholar

1986

\title{
A comparison of theory and life experiences in heteroculturality
}

Sara June Harper

Portland State University

Follow this and additional works at: https://pdxscholar.library.pdx.edu/open_access_etds

Part of the International and Intercultural Communication Commons Let us know how access to this document benefits you.

Recommended Citation

Harper, Sara June, "A comparison of theory and life experiences in heteroculturality" (1986). Dissertations and Theses. Paper 3601.

https://doi.org/10.15760/etd.5485

This Thesis is brought to you for free and open access. It has been accepted for inclusion in Dissertations and Theses by an authorized administrator of PDXScholar. Please contact us if we can make this document more accessible: pdxscholar@pdx.edu. 
AN ABSTRACT OF THE THESIS OF Sara June Harper for the Master of Arts in Speech Communication Presented November 20, 1986.

Title: A Comparison of Theory and Life Experiences in Heteroculturality.

APPROVED BY MEMBERS OF THE THESIS COMMITTEE:

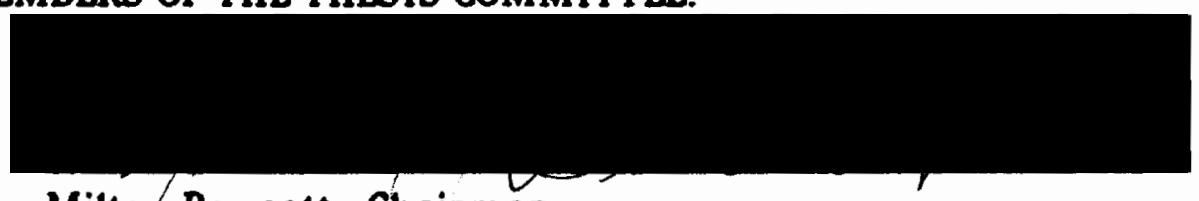

Milton Bennett, Chairman
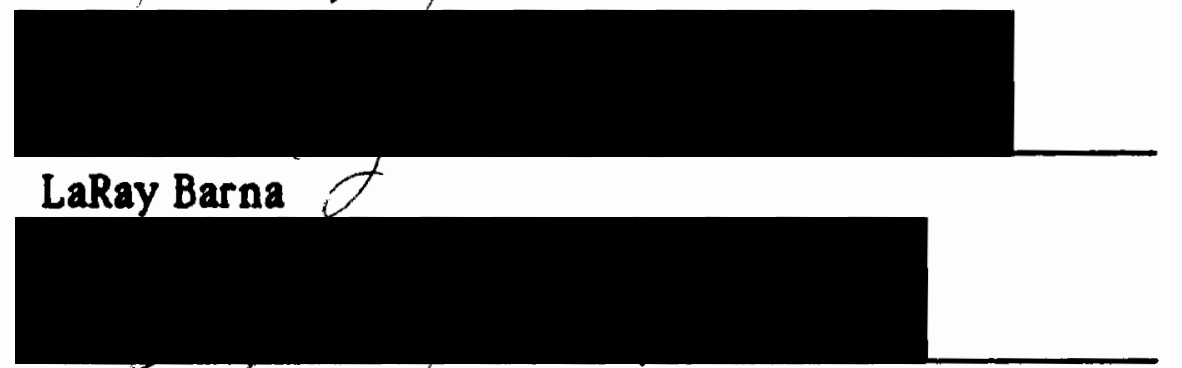

Stephen Kosokoff

This study is a comparison of theory and specific life experiences in heteroculturality. It synthesizes four conceptual frameworks describing individuals who have engaged in multiple culture-learning situations, and compares the themes derived from this synthesis with the attitudes and behaviors communicated by these multiculturally-socialized individuals.

This exploratory study utilizes the descriptive method of data collection and a qualitative method of data analysis. Research begins with a preliminary analysis of the theoretical concepts, themes, and categories presented by four prominent researchers, Peter Adler (1974), Stephen 
Bochner (1981). Everett Stonequist (1935,1961), and Ronald Taft (1981) as typical of "culturally marginal," "culturally mediating," or "multicultural" persons.

The results of this preliminary analysis are synthesized into five major categories containing the attitudinal and behavioral characteristics attributed to multicultural individuals. These categories are Multicultural Enculturation, Multicultural Transitions and Identifications, Multicultural Perspectives, Multicultural Stresses, and Multicultural Mediation Tendencies.

An interview schedule of questions generated from the synthesis of these theoretical constructs is used to interview a purposively selected study group of multiculturally socialized men and women having wide age ranges and cultural experiences.

This study then explores the congruence between the patterns analyzed and synthesized from the literature with the self-reported attitudes and behaviors of individuals who experienced primary socialization in three or more international environments. This takes place through a qualitative data analysis involving coding and refining all of the research data generated by the analysis of the selected literature and the purposive interviews. It culminates in the presentation of the salient themes surfacing as representative of the attitudes and behaviors of individuals exposed to multiple environments during their formative years, as well as a discussion of the non-emergent themes.

The results of this study have the potential for assisting counselors and other professionals who work with multicultural individuals. The themes which surfaced through the data analysis may serve as guides for enabling heteroculturals to recognize and cope with the particular stresses that appear to be related to experiencing cultural adjustment as a way of 
life during childhood. Systematic attempts to understand multiculturally socialized individuals, can help predict, organize, and clarify some of the particular attitudes, behaviors, and communication patterns characteristic of this group.

Situations in which specific applications of this information would be useful include: cross-cultural training and re-entry programs; refugee resettlement programs; schools and colleges; foster care programs; social services and health care; as well as business organizations that employ or work with people having multiple cultural affiliations. Even though the variables of racial, ethnic, and/or economic group dominance, and the motivation for cross-cultural involvement (choice for sojourners, versus necessity for refugees) are significant, there are notable commonalities among these groups of multiculturals that the information presented in this exploratory study may address. More specific research needs to be done in order to determine the most effective and culturally-sensitive strategies for each group. 


\title{
A COMPARISON OF THEORY AND LIFE EXPERIENCES \\ IN HETEROCULTURALITY
}

\author{
by
}

SARA JUNE HARPER

A thesis submitted in partial fulfillment of the requirements for the degree of

\author{
MASTER OF ARTS \\ in \\ SPEECH COMMUNICATION
}

Portland State University

1986 
TO THE OFFICE OF GRADUATE STUDIES AND RESEARCH:

The members of the Committee approve the thesis of Sara June Harper presented November $20,1986$.

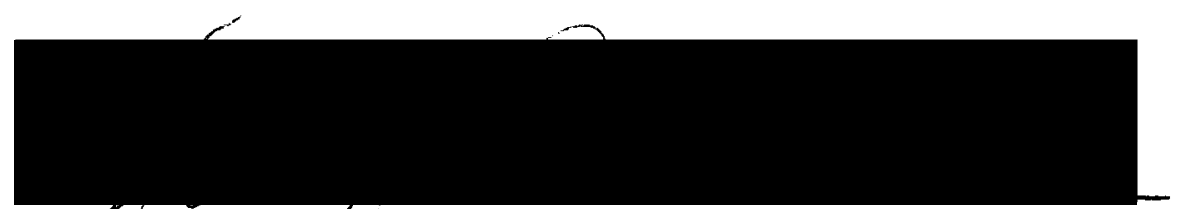

Milton Bennet, Chairman

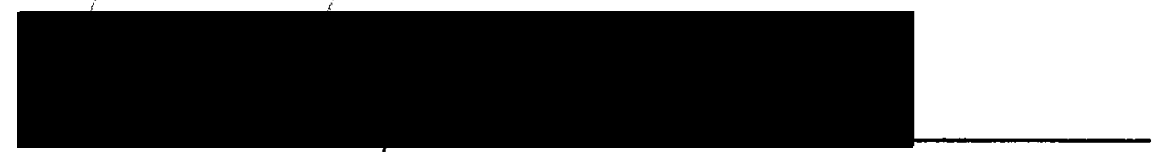

LaRay Barna

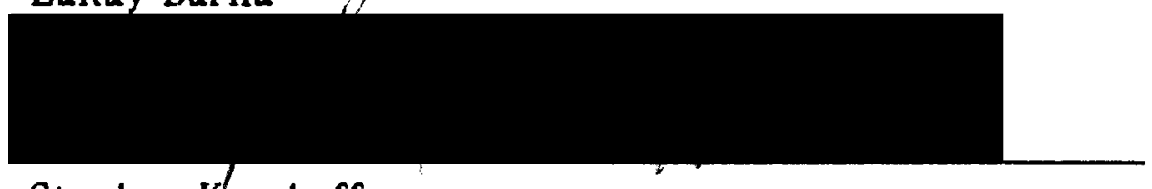

Stephen K'osokoff

APPROVED:

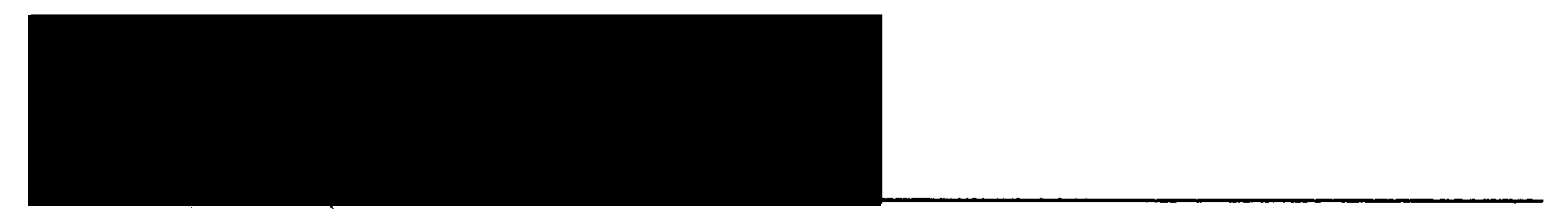

Mary Gordon, Shairman, Department of Speech Communication

Bernard Ross, Dean of Graduate Studies and Research 


\section{ACKNOWLEDGEMENTS}

I would like to take this opportunity to express my appreciation to the Speech Communication Department as a whole for providing an inspiring academic and personal educational experience. I would like to thank each of the professors who worked with me and encouraged me to grow. I especially appreciate the academic excitement and inspiration I received from studying with Dr. Theodore Grove, and with my advisor, Dr. Milton Bennett. I am also grateful for the hours Dr. Bennett spent helping me, for the times he showed his belief in me, and for the inspiration he gave me to pursue this thesis topic, which is and has been a very meaningful experience for me. I am grateful to Mrs. LaRay Barna for being there when I needed her, especially in my darkest hours when I wondered if I'd ever really finish writing this thesis! I would like to thank Dr. Stephen Kosokoff for being the exacting professor that he is, for scaring me, for encouraging me, and for making me laugh. I am thankful for the stimulation, warmth and encouragement Dr. Robert Vogelsang and Dr. Larry Steward, gave me through all the times I spent at PSU, the rough ones as well as the good ones. And, I would especially like to thank Pat Hamilton, for her amazing organizational skills and her willingness to help me, a growing person who still has alot to learn!

I appreciate the cooperation and interest exhibited by each person who participated in this study. Spending time with and getting to know each 
of them was a special opportunity for which I am very grateful. Each of them is a special individual from whom I learned quite a bit.

Without the invaluable assistance of Jan Van Marter and Joanie Thomsen the hundreds of pages of interview transcriptions, upon which this study is dependent, would never have been completed. I especially wish to thank Jan for not giving up on the difficult-to-understand tapes, as well as for the hours she spent showing interest in this project, and helping me learn to use the computer!

Most of all, 1 would like to express my deepest gratitude and appreciation to my wonderful parents, family, and friends, who have loved, assisted, encouraged, and put up with me through it all. Mom, Daddy, Steve, Jan, Beth, Rebecca, Ellen, Joanie, Derward, Riverose, Marco, and Dana, I thank each of you. 
TABLE OF CONTENTS

CHAPTER

PAGE

ACKNOWLEDGEMENTS iii

I INTRODUCTION

Rationale. 1

Research Questions..........................................................................................4

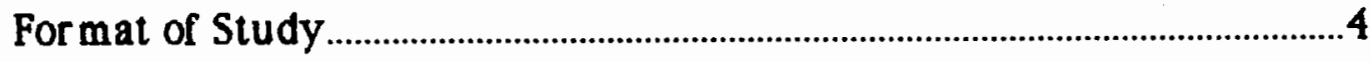

II THEORETICAL DISCUSSION

Definition of Terms

Historical Overview of the Literature............................................................... 10

Heterocultural Processes and Identity For mation........................................15

Stonequist's Life Cycle of Marginal Man .......................................................16

Taft's Model of the Making of a Multicultural..............................................19

Bochner's Theoretical Construct of culture Learning ...................................22

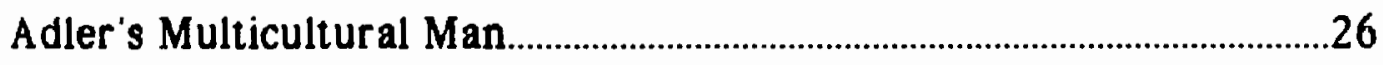

Synthesis of the Attitudinal and Behavioral Manifestations of

Multiculturality According to Stonequist, Adler, Bochner and Taft.....29

Multicultural Enculturation .................................................................30

Multicultural Transitions and Identifications....................................31

Multicultural Perspectives.........................................................................32 
Multicultural Stresses 34

Multicultural Mediation Tendencies. 35

\section{METHODOLOGY}

Purpose.

Overview 39

General Methods .40

Population and Subject Selection. 42

Interview Schedule of Questions. 44

Validity and Reliability..

Procedures.

Data Analysis .48

\section{RESULTS AND DISCUSSION}

Multicultural Enculturation........................................................................50

Multicultural Transitions and Identifications............................................56

Multicultural Perspectives.............................................................................61

Multicultural Stresses........................................................................................6

Multicultural Mediation Tendencies............................................................72

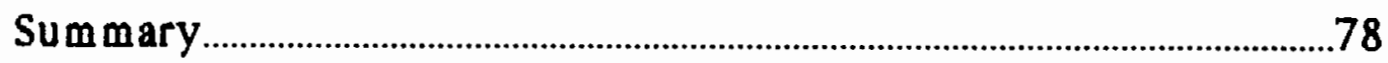

V LIMITATIONS, APPLICATIONS AND SUGGESTIONS FOR FURTHER STUDY

Limitations.

Practical Applications 
Suggestions for Further Research.

BIBLIOGRAPHY

\section{APPENDICES}

Appendix A - Preliminary Thematic Analysis.............................................98

Appendix B - Demographic Screening Instrument..................................100

Appendix C - Primary Enculturation

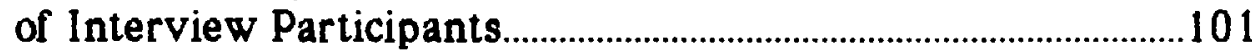

Appendir D - Interview Schedule of Questions.....................................105

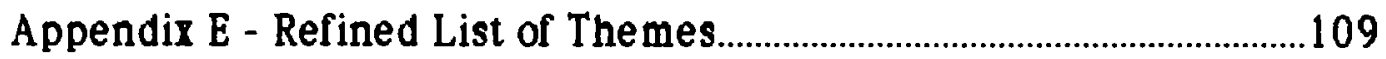




\section{CHAPTER I}

\section{INTRODUCTION}

\section{Rationale}

From the moment of birth, we begin to be members of human society through our interactions with others. These interpersonal contacts develop within us a deeply rooted concept of what we believe is the only real and conceivable world. Berger and Luckman (1967) have called this process primary socialization. It is the process through which we develop our first ordered view of the world. The internalization of this world view provides us with a contert that defines and limits our sense of reality and enables us to perceive the everchanging, dynamic world we live in as relatively stable, orderly, and predictable (Hall, 1976). It becomes such an intrinsic part of us that we are not aware that our very perceptions are governed by this world view. In Singer's (1976) words:

The way we perceive the world, what we expect of it, and what we think about it, is so basic and so ingrained, is buried so deep in us and in our consciousness, that we continuously act and react without thinking why--without even realizing that we might think why. (p. 7)

These perceptual choices are largely determined by the particular culture in which we live and are socialized during our formative years. The value systems, beliefs, and attitudes, of those with whom we come into contact, paint for us a multidimensional view of what is. Each interaction 
helps us formulate our own individual identities, or personalities, within the parameters of our exposures. What we are exposed to and how our experiences can be interpreted and evaluated is determined by the boundaries of the culture that enfolds us. Through these cultural boundaries we learn how to develop relationships with others, express emotions, control behaviors, satisfy basic urges, and communicate with others as expected (Berger and Luckman, 1967). The ability to function successfully within a given culture is dependent upon the acquisition of these culturallyappropriate skills.

Individuals who experience primary socialization in two or more cultural milieur may acquire and internalize each set of cultural expectations and develop multiple patterns of emotional, behavioral, and communicative response. The subsequent overlap of more than one set of cultural assumptions provides the opportunity for conflicts to occur within the individual. It also provides a context in which the individual may develop a superior ability to understand and negotiate these cross-cultural conflicts both internally and externally (Adler, 1974; Bochner, 1981; Stonequist, 1935; Taft, 1981).

Individuals who have dual or multiple cultural affiliations are described from a number of theoretical perspectives by experts in the fields of intercultural communication, sociology, psychology, and anthropology. Each writer describes the unique skills as well as the stresses particular to individuals who acquire two or more cultural worlds. However, there is very little empirical information concerning how individuals respond to two or more socializing influences either simultaneously as in the case of bi/multicultural childhoods or successively as in the case of adult culture 
learners (Bochner,1981). The terminology used to describe this phenomenon is not at all unifor $m$, although there is considerable conceptual overlap.

An investigation of the effects of early exposure to more than one culture is significant to the field of intercultural communication, and it is also timely, as the amount of cross-cultural contact has increased substantially in the last decade and is continuing to do so. More and more people are finding themselves involved in cross-cultural interface situations where the possibilities for dual or multiple culture-learning takes place. Several researchers have stated that these intercultural experiences have a profound psychosocial influence on individuals who live and work for ertended periods of time in countries to which they are not natively born (Brislin, 1981 ; Bochner, 1981; Taft, 1981 ; Useem, Useem, and Donoghue, 1963 ). The impact of these experiences may have influenced the lives of the individuals who spent their formative years as children of these sojourning parents even more profoundly (Werkman, Farley, Butler, Quayhagen, 1982).

A primary socialization process involving exposure to more than two international environments with distinct cultural perspectives and separate world views may create a psychocultural development pattern that is recognizably distinct from the development pattern of individuals socialized within a single culture (Adler, 1974; Bochner, 1981; Downie, 1976; Gleason, 1970; Stonequist, 1935; Taft, 1981; Werkman, et al. 1982). Socialization within several cultural milieur has the potential of formulating individuals who are adept at cultural mediation and synthesis of groups, as well as persons who are vulnerable to a wide range of stresses particular to those having multiple cultural experiences and affiliations (Stonequist, 1935; Gleason, 1970; Adler, 1974; Bochner, 1981; Taft, 1981 ). 
This study seeks to provide a synthesis of the conceptual frameworks describing the individuals who have engaged in multiple culture-learning situations and have been termed "marginal," "multicultural," or "mediating" persons in the literature; and, to provide a preliminary empirical exploration of the attitudes, and behaviors communicated by these multiculturallysocialized individuals. The following research questions are pursued:

\section{RESEARCH QUESTIONS}

1) To what extent can common themes be derived from the theoretical descriptions of multiculturality proposed by four prominent researchers of this topic: Everett Stonequist, Peter Adler, Stephen Bochner, and Ronald Taft?

2) To what extent are the subjective reports of the attitudes and behaviors of individuals who have experienced primary socialization in three or more international environments consistent with the theoretical treatments?

\section{Format}

Chapter $I$ is an introduction to this thesis. It includes the rationale for the study, the research question, and this general format.

Chapter Il presents a theoretical discussion, or background, for the issues addressed by the study. This discussion presents: a definition of terms as they are used for the purposes of this study; an historical overview of the literature; and the selected author's descriptions of heterocultural development processes and identity formation. These developmental processes are: Stonequist's $(1935,1961)$ "life cycle of marginal man;" Taft's 
(1981) "model of the making of a multicultural;" Bochner's (1981) "mediating person/culture learning construct;" and Adler's (1974) "multicultural man."

Chapter II also addresses the first research question concerning the extent to which common themes can be derived from the theoretical descriptions of multiculturality. This is accomplished by presenting a synthesis of the attitudinal and behavioral manifestations of multiculturality commonly described by the surveyed authors. This synthesis is divided into five sections which represent the surveyed authors major areas of focus. The sections are: Multicultural Enculturation; Multicultural Transitions and Identifications; Multicultural Perspectives; and Multicultural Mediation Tendencies.

Chapter 111 presents the methodology employed in this research. It provides a statement of the design of the study including the purpose and an overview. Also described are the general methods, the targeted population and subject selection, the interview schedule of questions, a discussion of validity and reliability relevant to this study, the procedures utilized, and the qualitative phases of data analysis.

This methodology explores whether or not adult individuals who experienced primary socialization in three or more international environments develop certain recognizable attitudes and behaviors that are reflective of their early enculturation experiences.

Chapter IV presents the results and discussion of the research. The data collected from the interviews is related to the second research question which explores the extent to which the subjective reports of the individuals who experienced primary socialization in three or more international environments are consistent with the themes synthesized from the literature. Chapter IV is summarized with a brief presentation of the themes 
that emerged from the literature as well as the interview data as characteristic of the interview participants' multicultural experiences.

Chapter V presents the limitations of this study, a discussion of some practical applications for which the study results may be used, and some directions for future research. 


\section{CHAPTER II \\ THEORETICAL DISCUSSION \\ Definition of Terms}

Culture is described by Redfield (1941) as the perspective shared by those of a particular group. According to Shibutani (1955) it is not a static entity, but a continuing process in which norms are constantly being reaffirmed in social interaction. For the purposes of this paper, the term "culture" will include these concepts as stated in the comprehensive definition provided by Hoopes and Pusch (1981):

Culture is the sum total of ways of living, including values, beliefs, esthetic standards, linguistic expressions, patterns of thinking, behavioral norms, and styles of communication which a group of people has developed. (p. 3)

People within a cultural group support one another's perceptions, and perspectives by continuously responding to one another in expected ways. In this sense, culture is a product of communication (Shibutani,1955).

The concept of reference sroup refers to the organization of our experience through the unconscious adoption of the attitudes and values of the cultural community in which we participate. This process occurs through the development and internalization of a sense of what Mead (1934) termed 
the"generalized other," which represents the organized responses of all members of the group. This "generalized other" or "reference group" provides us with the cultural norms we use as anchoring points in structuring our perceptual field. We do not necessarily like or aspire toward acceptance in a group that serves as a reference for us. As members, we may despise the reference group to which we belong, but still be heavily influenced by it and see the world largely through its eyes (Shibutani,1955). Hence, even if we make a radical change in social or economic status and reject or deny membership in the group to which we belong, that group still serves as a reference or "generalized other," whose viewpoint is very much a part of our "world view," or "perspective."

Our world view or perspective is the "reality" we experience as depicted by our cultural reference group. Barnlund (1975) states that it is a set of culturally-determined perceptual filters that guide our thoughts, actions, and expectations which are so much a part of us that we do not recognize that they exist. Although our world view may confine us, it also protects us by providing us with a sense of structure that gives meaning to our experience. This concept of a cultural perspective that defines reality for us is congruent with the following statement made by Edward T. Hall (1976):

One of the major functions of culture is to provide us with a "highly selective screen" that designates what we pay attention to and what we ignore. It is precisely because this perceptual screening process is out of awareness that we are conditioned to accept the one "reality" defined by our cultural reference group as absolute. (p. 85 ) 
The term intercultural refers to interactions between members of different cultural groups.

The term cross-cultural refers to conceptual and comparative discussions of culture.

Culture-learning as defined by Bochner (1981) refers to changes that occur within the individual as a result of immersion in an intercultural interface situation whereby it is assumed that that even though cultures are more complex, individuals can learn a second culture in much the same way as they can learn a second language.

For the purposes of this paper, culture-learning involves the process of internalizing the values, beliefs, esthetic standards, linguistic expressions, putterns of thinking, behavioral norms, and styles of communication adhered to by the members of a given culture.

Monocultural people are those individuals who have been socialized within one cultural domain, and who have internalized the values, beliefs, esthetic standards, linguistic expressions, patterns of thinking, behavioral norms, and styles of communication espoused by the members of the given culture.

Bicultural people are those individuals who have been socialized within two cultural domains, and exposed to the values, beliefs, esthetic standards, linguistic expressions, patterns of thinking, behavioral norms, and styles of communication espoused by the members of two cultures . 
Heterocultural people are those individuals who have been socialized within two or more cultural domains, and exposed to the values, beliefs, esthetic standards, linguistic expressions, patterns of thinking, behavioral norms. and styles of communication espoused by the members of each culture. This term is used globally to include both bicultural and multicultural connotations.

Multicultural people are those individuals who have been socialized within three or more cultural domains, and exposed to the values, beliefs, esthetic standards, linguistic expressions, patterns of thinking, behavioral norms, and styles of communication espoused by the members of the given cultures.

\section{Historical Overviev of the Literature}

Following is an overview of the literature concerning individuals who have had dual or multiple cultural involvements and affiliations. Certain theoretical descriptions of "marginal," "multicultural," and "mediating" persons are the focus of study. The selected models include Stonequist's (1935,1961) presentation of the "marginal man," Adler's (1974) description of the "multicultural man," Bochner's (1981) model of the "mediating person," and Taft's (1981) exploration of multicultural enculturation. The contributions of other authors will be included as they enhance the conceptual clarity and understanding of heterocultural existence. Although the emphasis of this study is on multicultural development during the formative years, the scope of this historical perspective provides a more 
comprehensive overview of the concepts and terminology presented in the literature. Of major significance in this area are the varied meanings assigned to the term "marginality" by scholars in the fields of sociology. cross-cultural psychology and intercultural communication.

The term "marginality" is used to refer to the heterocultural position of living with two or more cultural reference groups by many of the social scientists discussing this phenomenon (Goldberg. 1941: Lum, 1977; Park, 1928: Secord and Backman. 1964; Shibutani, 1961; Stonequist, 1935; Sue. 1981: Willie, 1975; etc.). The concept was first introduced by the sociologist R.E. Park (1928). His major works are concerned with the investigation of inter-ethnic contacts. Park represented the "marginal man" as:

a cultural hybrid, a man living and sharing intimately in the cultural life and traditions of two distinct peoples; never quite willing to break, even if permitted to do so, with his past and his traditions, and not quite accepted, because of racial prejudice in the new society in which he now sought to find a place. He was a man on the margin of two cultures and two societies which never completely interpenetrated and fused. (p.892)

Park's work is elaborated upon by Stonequist (1935), who made further investigations into the realms of "marginal men." Stonequist found that upon analysis, racial mixture proves to be somewhat incidental in the incidence of marginality. He claims that the racial hybrid is likety to be marginal not because of mixed blood, but because this mixture places one in a certain social situation. Stonequist (1961) studied racial and cultural hybrids in India, South Africa, the United States, Jamaica, Java, Hawaii. Brazil, and Europe. He developed a theoretical description that includes the life cycle of the marginal man, his personality characteristics, as well as the different roles he is likety to assume in the societies he straddles. 
Stonequist's (1935.1961) works are considered some of the most comprehensive and influential in the study of cultural marginality. His writings are quoted in journals of psychology. sociology and communication.

Goldberg (1941) summarizes the essential position of the marginal man as that of an individual shaped and molded by one culture, brought by migration, education, $\alpha$ other influence into permanent contact with a culture of different content; or, as an individual who has been initiated into two or more historic traditions, languages, political loyalties, moral codes, or religions. Thus, the marginal man, as perceived by Goldberg, is a person who lives on the edge of each culture, is influenced by both, but is a member of neither. The concept of the marginal man is further discussed by several others including: Secord and Backman (1964), Shibutani (1961), and Willie (1975). Each of these researchers describes, qualifies, adapts, and applies the positive and negative aspects of the marginal position espoused by Park and Stonequist.

Bochner (1981) discusses the same dilemma using a slight variation in terminology. He calls the lost individual caught between cultures a victim of the "marginal syndrome," and the successful, synthesizing individual the "mediating person." Adler (1974) writes about similar issues in his description of the "multicultural man" whose psychocultural framework is formed through a successive process of disintegration and reintegration of the psyche. This occurs as new cultural frameworks are internalized and impinge upon the old. This process enables the multicultural person "to help others negotiate the cultural realities of a different system." (Adler, 1974). Thus, the "mediating individuals" Bochner (1973) describes "incorporate the essential characteristics of multicultural man" (Adler,1974). Taft (1981) proposes a comprehensive model which differentiates between the various 
types of multicultural development and categorizes them according to the age, circumstance, and attitude of the individual during each cross cultural involvement. He describes the potential for each type of multiculturallysocialized individual to develop the mediating qualities Bochner defines. Both Stonequist and Taft are principally concerned with the psychosocial enculturation processes of individuals experiencing primary socialization within two or more cultures, whereas Bochner and Adler also address the effects of culture learning on the formation of multicultural identities later in life. The individuals Taft considers successful at cultural mediation are those he defines as "primary familiogenic multiculturals," or, people born into heterocultural environments. Taft reports that this category encompasses the "third culture kids." described by Ruth Useem.

Useem (1976) explores the unique cultural position of those she terms "third culture kids" or "TCK's," who have grown up in foreign countries as dependents of parents employed overseas. Although they grow up in foreign countries, they are not integral parts of those countries, nor do they feel at home in their country of citizenship. Useem claims that they do not feel at home in the native countries of their parents because TCK's do not know the expectations of others and do not feel a sense of belonging. Downie (1976) notes that re-entry into the country of citizenship for TCK's often results in social marginality due to the lack of a clearly definable group with which they can relate. This position is supported by Gleason (1970) who also emphasizes a significant difference in the worldmindedness of overseasexperienced American youth and their peers who have never lived outside the United States.

The writings of cross-cultural psychologists and psychiatrists often focus on the pathological aspects of the marginal position. Counselors 
working with minority clients define marginality as a position in which a minority group member has absorbed attitudes and values of the dominant culture to the point that one's personal identity becomes confused. According to Sue (1981):

Marginal individuals deny the existence of racism; believe that the plight of their own people is due to laziness, stupidity, and a clinging to outdated traditions; reject their own cultural heritage and believe that their own ethnicity represents a handicap. (pp. 83-85)

Sue has identified the key issue here as the dominant-subordinate position between two cultures. Sue is supported in this view by many researchers in his field (Brody, 1963; Clark and Clark, 1947; Derbyshire and Brody, 1964; and Friere, 1970). "Biculturality" is the term used to describe minority group members who are adjusted to the likenesses and differences between the cultural groups to which they belong and within which they can function satisfactorily (Sue,1981).

Lum (1977) describes a marginal person as one whose actions do not clearly reflect any one culture. He claims that because they do not act like members of any one group, marginal people can "transcend boundaries, see new patterns, and attempt to bridge gaps." Marginality is a difficult position to live with, yet this generally broadminded and unchauvinistic influence is an essential component of a healthy social system. Lum makes a case for the development of a more balanced view of marginality which might increase the recognition of the assets of each culture and prevent further suggestions that outgroups change their behavior to be more like that of in-groups.

Bennett's (1984) training model on the development of intercultural sensitivity also emphasizes the positive aspects of the marginal position. 
According to Bennett, intercultural sensitivity develops along a contiuum beginning with ethnocentric states and advancing through what he terms "ethnorelative states," towards an end position of "constructive marginality." Bennett (1984) states that; "constructive marginality is the experience of one's self as a constant creator of one's own reality." The negative aspects of a sense of marginality may be ameliorated by taking a "nondevelopmentally marginal person" through a training course involving the stages of intercultural sensitivity, and then labeling the "outsider" position as both marginal and constructive. This would enable them to construe their experience of personal 'differentness' as a natural outgrowth of a highly developed sensitivity to cultural relativity" (Bennett, 1984).

The literature has described the "tragic" or "transcendent," "adjusted" or "maladjusted." "constructive" or "self-destructive" position of these culturally marginal, heterocultural individuals. Yet, each writer has presented another variation in meaning and/or terminology. Thus, consistency and clarity in the definitions and discussions of heterocultural positions has not been reached. The concept of "marginality" is the major theme of these writings; however, exactly what this term defines or which term is used to label this theme is not at all uniform throughout the literature.

\section{Heterocultural Develooment Processes and Identity Formation}

The following discussion looks more carefully into the heterocultural development processes described by each author for the purpose of defining the concepts necessary for the exploration of the research questions. It is a summary of each author's concept of multicultural identity formation. It 
includes; Taft's (1981) "model of the making of a multicultural;" Bochner's (1981) "mediating person/culture learning construct;" and Adler's (1974) "multicultural man."

\section{Stonequist's Life Cycle of Marsinal Man}

The social situation which Stonequist describes as producing the marginal type of personality is a bi- or multicultural one in which some individuals find themselves on the margins of two or more societies, partly in and partly out, such that they internalize the contrasts, tensions, or conflicts of each culture. Stonequist's model of the life cycle of marginal man is based on the premise that the groups have a relationship of inequality, whether or not this is openly asserted. It is the subordinate or minority group members whose social contacts lead them to become partially assimilated and psychologically identified with the dominant group that are in the marginal position. Stonequist distinguishes two types of marginal situations: one where the cultural difference includes a racial or biological difference; and the other where the difference is purely cultural. The three stages of development roughly correspond to 1) the protected environment of childhood; 2) the widening social contacts and ensuing conflicts of adolescence; and 3) the necessary accommodations of maturity.

Many of the writers and researchers who have quoted Stonequist's work have emphasized only the negative aspects of his original treatment of the marginal man. Whereas Stonequist explicitly describes the problems and difficulties experienced by individuals who must eternally recognize their position as natively outside any one cultural group, he does not state that this position is inherently unhealthy or tragic. The negative interpretation of 
Stonequist's marginal man is only a partial view of the individuals he researched. In his own words Stonequist (1935) denies the singularly negative description of marginality saying:

A notion that the marginal man is necessarily "abnormal," "unhappy," or otherwise unfortunate appears to have arisen. This is a misconception of the facts, a narrowing of the concept to the more disorganized cases. The marginal individual may in fact profit by his special position and develop a superior mind. He may become a leader, teacher, conciliator, aggressive nationalist or revolutionary, just as well as he might fall into mental instability, delinquency, crime, or suicide. The ability to resolve the internal conflicts brought about by one's marginality will determine the outcome of its expression. (pp.11-12)

The first stage of development in the life cycle of marginality Stonequist (1935) describes is the "stage of preparation" during which the individual is introduced into the two cultures, and is socialized by both. At this stage one does not realize that two distinct cultures are being assimilated, as it occurs unconsciously during childhood. However, it is this process of assimilation into more than one distinct cultural group that makes it possible for the later conflict of loyalties inherent in the marginal personality to occur. There is no consciousness of cultural or racial differences during this childhood stage of preparation.

Stonequist describes the second stage as having the character of a "crisis." During this period the individual, through one or more defining experiences, becomes aware of the cultural conflict. This "crisis" may occur as a result of a single experience, or may dawn on the individual in a more gradual, imperceptible manner that one cannot clearly identify. The individual's life organization is seriously disturbed and may result in shock, restlessness, disillusionment, and estrangement. This is due to the development of a new self-consciousness which mirrors the newly realized 
situation and causes the marginal person to take in the attitude which each of the two groups has toward the other. Thus the individual becomes a divided personality. The more completely the individual assimilates the culture of the dominant group, the greater are the individual's confusion and difficulty when exclusion from the dominant group occurs.

The marginal person does not remain passive, but strives toward readjustment. It is a stressful experience, states Stonequist, that is peculiarly conducive to thought. The stimulus of the situation may create a superior personality or mind." Stonequist considers this to be a plausible reason for the superiority of ten shown by Jews and individuals with mixed blood.

During the third stage, the individual's more enduring responses surface and may be directed toward: 1) membership in the dominant group; 2) membership in the subordinate group; 3) some form of accommodation, between the two groups; or 4) complete withdrawal and isolation from either group. Thus, as culturally-marginal individuals adjust their relationships with their particular reference groups, the foundations of their individual identities are formed.

Stonequist describes three common roles into which culturallymarginal individuals may evolve in order to resolve the inner conflicts inherent in their heterocultural positions: the assimilationist role, the nationalist role, or the intermediary role. The assimilationists reduce or solve the stress of living between-cultures by seeking and finding acceptance in one of the cultural groups, and sublimating, or pushing the inner conflicts below the surface of consciousness. The nationalists become champions of the subordinate group, often assuming leadership roles that enable them to address the pain of personal exclusion from the dominant 
group by fighting discrimination at large. The inter mediaries develop insight into each culture. The degree to which intermediary marginals are successful in using their cultural understandings enables them to resolve their own inner conflicts and adjustment issues.

Stonequist claims that individuals who become multicultural through participation in more than two cultures become richer personalities, as they are able to shift from one language and set of values, habits, and attitudes to another. They develop what he termed an "international mind." This means that they instinctively grasp the meanings and values of each culture in which they move. They are thus in a position to look at problems from more than one viewpoint and see the essential ethnocentrism of each.

\section{Taft's Model of the Making of a Multicultural}

Taft's (1981, pp. 53-88) developmental model of multiculturalism and the potential for becoming a competent cultural mediator is formulated upon an enculturation point of view. Enculturation, is the process through which an individual acquires culture. It is an interactive process involving an interplay between the individual and the society from which one is learning the specific human social skills necessary to survive in that culture. This enculturation process provides the rules that guide one's cognitions, evaluations, and behaviors.

Taft's reference to early enculturation, or primary socialization, corresponds to Piaget's preoperational stage of development which takes place between two and six years of age. The effects of early emotional conditioning and associations with objects and events that develop during primary socialization are especially hard to change. Thus, a person will tend 
to respond to the experiences of later years in accordance with the responses they establish during primary socialization even when the circumstances in which they were formulated no longer apply.

Later enculturation occurs during adulthood. It is dependent on and limited by the nature of one's primary socialization. Enculturation at a later stage of life may enable one to achieve the cognitive adaptations to appear outwardly to have acquired the new culture. Inwardly, however, the emotional responses developed during the formative years do not change.

An individual's potential for becoming a cultural mediator is strongly affected by the nature of these ingrained patterns. This becomes especially apparent when one's emotional responses to a situation in a second culture vary significantly with the responses of the second culture's members.

The differences between individuals who acquire multiculturality simultaneously during childhood, and those who acquire it after the foundation for their first culture has been firmly established are important to the competence with which the individual is likely to manage the secondary culture. The major factors considered by Taft in his assessment of an individual's ability and inclination to play the role of mediator are 1) consideration of the age at which exposure to the cultures involved occurred; 2) the circumstances of the exposure; and 3) the attitudes toward the cultures involved in that exposure.

Taft proposes that the making of a multicultural takes place through one or more of four enculturation processes, the first two are familiogenic and the second two are idiogenic:

1) Primary Familiogenic Multiculturalism; represents a situation in which primary socialization simultaneously includes more than one culture. Taft has likened this position to what Swain (1972) has called having 
biculturalism as a first culture, and to what Useem et al. (1963) have described as belonging to a third culture. Primary Multiculturalism may occur simultaneously in three different ways: 1) through someone in the home, such as a parent or grandparent, who has a cultural background unlike that of the dominant society and who provides a cultural contrast that contributes different elements to the child's enculturation; 2) through having one or more bicultural parents, providing the opportunity for the child to be brought up with biculturality as part of his/her self-concept; 3) through socialization into a mixed community whereby the child is simultaneously subjected to diverse learning between home and the outside culture.

2) Family in Transition is a second type of familiogenic acquisition of more than one culture. In this case, the family is in the course of change during the individual's primary socialization period. This is exemplified by the upwardly mobile immigrant family that moves from the slum district of initial settlement to a middle class settlement. In this case, the entire family is enculturated into the middle class majority culture.

3) Primary Ideosenic Biculturality describes the movement by an individual child from one culture to another during the primary socialization period. If this transition of parental models occurs smoothly, it is likely to lead to the replacement of the first culture by the second. Children adopted by parents of different racial backgrounds may experience periodic rejection by their environments. These situations present them with the need to contend with their mired identities. Alienation, and conflict, accompanied by a sense of not belonging are also likely to occur.

4) Secondary Idiogenic Biculturality is the acquisition of secondary cultures as a result of exposure to new cultures after the age of seven years, 
When the most crucial period of primary socialization has already occurred. This exposure may range from indirect contact, to an all encompassing involvement in a new culture that entirely cuts one off from one's original culture other than through memories. Taft claims that one's feelings of identity, basic values and cognitive style are unlikely to change completely after this crucial socialization period even though one's language and other skills relevant to the original culture may fade from memory.

Taft ties early enculturation to identity formation. He also makes the case that multicultural experiences during the primary enculturation process are significantly different from monocultural experiences. Taft concludes that the differences generated by multicultural enculturation processes will substantially affect the individual's potential success as a mediating person. The person whose early socialization is heterocultural is likely to have more cognitive fleribility than a monoculturally socialized individual and is better suited to perform cultural mediation roles.

\section{Bochner's Theoretical Construct of Culture-Learning}

Bochner's (1981, pp.12-15) theoretical construct of culture-learning refers to changes that occur within an individual as a result of immersion in an intercultural interface situation. Theoretically, four broad outcomes are possible in which an individual may: 1) remain monocultural by rejecting all alien influences and clinging to the culture of origin; 2) reject the original, and adopt a new culture; 3) become bicultural by retaining the original culture and also learning a second culture; 4) become multicultural by retaining the original culture and also learning several other cultures. 
Bochner's culture-learning model has eight assumptions upon which it is based:

1) Even though cultures are more complex, an individual can learn a second culture in the same way as one acquires a second language.

2) Culture-learners do not only acquire secondary cultural skills and knowledge. but they also develop feelings and attitudes about what they encounter.

3) It is essential to distinguish each of the three strands of culturelearning: cognitive, skill, and affective development. Individuals who know, are competent in, and like their intersecting cultures can be expected to be more effective mediators than individuals who know but disapprove of one or more of the cultures concerned.

4) In the process of culture-learning. one may acquire a sense of cultural relativism, the doctrine proposed by Herskovits (1948) that all practices are valid if they are sanctioned by the norms and traditions of their indigenous society.

5) The more cultures one knows, the stronger the commitment one will have toward cultural relativism.

6) Persons familiar with several cultures, have richer and more variegated inner experiences than mono- or bicultural individuals. 
7) Multicultural individuals are likely to make better mediators and are likely to function as mediators in a wider variety of intercultural interface situations than are biculturals.

8) The process of one's progression from mono- to heteroculturality is correlated with one's capacity to mediate between cultural systems and in part, accounts for this capacity.

According to Bochner, the relationship between the mediating person and the marginal man Stonequist describes, is that while the mediating person can be thought of as linking two or more cultural groups, the marginal person is someone who has fallen between the various social systems. The marginal person's difficulty consists of simultaneous identification with conflicting or incompatible reference groups. Thus, one is of ten required to enact incompatible roles. This situation creates considerable personal anguish for the marginal person, though society frequently benefits. Many individuals who fit this criteria of marginality also function as cultural mediators. Bochner illustrates this concept with the following passage from Nehru's (1936) autobiography that expresses the feeling of marginality far more poignantly than any social scientist's description:

I have become a queer mixture of the East and the West, out of place everywhere, at home nowhere. Perhaps my thoughts and approach to life are more akin to what is called Western than Eastern, but India clings to me, as she does to all her children, in innumerable ways; and behind me lie, somewhere in the subconscious, racial memories of a hundred, or whatever the number may be, generations of Brahmans. I cannot get rid of either that past inheritance or my recent acquisitions. They are both part of me, and though they help me in both the East and the West, they also create in me a feeling of spiritual loneliness not only in public activities, but in life itself. I am 
a stranger and alien in the West. I cannot be of it. But in my own country also, sometimes I have an exile's feeling. (p.598)

Bochner's distinction between marginality and mediation represent little more than two sides of the same situation. Rather than discussing the phenomenon in terms of "positive" and "negative" or "constructive" and "destructive" marginality, Bochner labels the individual who successfully manifests the positive aspects of living between cultures a "mediating person." While Bochner recognizes that individuals located at what he calls the "interface between two cultural systems," cannot avoid the marginal syndrome altogether, it is desirable to minimize the risk of falling between the cultural systems in question. Por Bochner the essential difference between marginality and mediation is the response of the two individuals; while the marginal person responds to the different cultures identified with as if they were mutually incompatible, the mediating person attempts to find ways of coordinating and reconciling them. The mediating person is active, and is frequently involved in communicating, clarifying, persuading, even wheeling and dealing. The mediating person is a creative synthesizer attempting to create new concepts out of the diverse elements encountered in different worlds. Although multiculturality itself is associated with growth, a large range of expressive options, and future oriented, creative work, it is difficult to be in a minority position, especially one that is significantly different from the majority position. Thus, for multiculturals to emerge as the dynamic mediators they have the potential of becoming. rather than sink into the anomie of a "between-culture" position, they would benefit by associating with groups having shared norms, as well as interpersonal and institutional supports for their emerging supranational roles. 


\section{Adler's Multicultural Man}

The multicultural man Adler (1974, pp. 23-40) describes is a human being whose identity is formulated through a process that differs from others both sociologically and psychologically. The multicultural man incorporates culturally-diverse life patterns and definitions of reality into one paradoxical psyche. In Adler's own words:

We call this new type of person multicultural because he embodies a core process of self verification that is grounded in both the universality of the human condition and in the diversity of man's cultural forms. ... Multicultural man is the person who is intellectually and emotionally committed to the fundamental unity of all human beings while at the same time he recognizes, legitimizes, accepts, and appreciates the fundamental differences that lie between people of different cultures. (p.24)

Adler's discussion of the multicultural man does not address the developmental conditions under which multicultural identities are formed. However, he does assert that the evolution from a cultural identity to a multicultural one is most likely to occur where the foundations of collective cultural identity are disturbed and individuals are faced with new exposures to other ways of life. Thus, Adler infers from the investigations of crosscultural psychologists and anthropologists that the multicultural identity is shaped by the stresses and strains of intercultural involvement at both the macro and microcultural levels. The multicultural style surfaces when the individual is able to negotiate the conflicts and tensions arising from these cross-cultural encounters. Multicultural man is continually involved in the repeated experience of adaptation to new dimensions of experience and perception. This cyclic pattern often produces forms of personality disintegration. Adler's conception of the multicultural man is an individual 
whose being is formulated on a model of what Dabrowski (1964) names "positive disintegration." Dabrowski describes this process as an evolutionary cycle involving the three basic steps of integration and disintegration. The cycle begins at a primary, or low, level of personality integration; dissatisfaction and disintegration occur; and reintegration at a higher level, of personality integration takes place. Implicit in Dabrowski's model is a continuous movement toward growth with each cycle of positive disintegration and reintegration at a higher level.

Adler claims that multicultural individuals can be defined by a psychocultural identity pattern that is not at all similar to the relatively stable forms of self process found in the cultural identity pattern. The concept of cultural identity Adler refers to is a collective self-awareness that members of a given group share with one another. It includes the attributes defined by Hoopes and Pusch (1981) as belonging to culture, internalized through a process of identification with significant others. This process is termed primary socialization by Berger and Luckman (1967) or early enculturation by Taft. It is the largely unconscious patterning of perceptions shaped by cultural values and attitudes towards life, death, birth, family, children, god, and nature.

From Adler's perspective, the multicultural identity has three major characteristics that differentiate it from the traditional structure of cultural identity:

1) Multicultural persons are psychoculturally adaptive. They maintain situational connections in their relationships to others and to the cultures with which they are affiliated. They have no clear boundaries between themselves and the varieties of personal and cultural contexts they participate in. Their identities are formulated upon the shifts and changes 
encountered in life's experiences rather than upon a single mental image of a heirarchical structure, as are cultural identities. Their beliefs, and world views are not permanently internalized, but evolve and reformulate in order to maintain contextual relevance. They are therefore dependent more on the necessities of experience than on the predisposition of a single culture. Multiculturals do not judge one situation in terms of another, so they must continuously evolve new systems of evaluation that are conteztually relevant and appropriate to each situation.

2) Multicultural persons often undergo personal transitions. They frequently recreate their identities through a process of culture learning and un-learning. They are eternally involved in psychological quests, explorations, and experiments, as well as in the reformation of their own self images through their experience and contact with the world.

3) Multicultural persons maintain indefinite boundaries of the self. The parameters of their identities are not fired or predictable, but open to change. Their psychocultural styles are relational and in movement, and their needs, drives, motivations and expectations are of ten realigned to fit the conterts they are in. Multicultural people can never totally accept the demands of any one culture, nor are they ever totally free from the conditionings of their cultures. They are, however, able to look at their original cultures from an outsider's perspective. This tension develops a dynamic, and critical position towards totalistic ideologies, systems and movements.

Both Stonequist and Adler describe multicultural identities as inherently relational and in movement. These fluid personality structures are formulated through processes of trauma and change. Stonequist describes the marginal personality as arising out of a "crisis" experience in 
which the individual's life organization is seriously disturbed by the recognition of the culturally conflicting situation in which s/he exists. Both Stonequist and Adler describe the identity crisis as a situation involving confusion, shock, restlessness, and estrangement that leads the individual to develop a new self-conciousness. In Dabrowski's terms, it is a process of personality disintegration. Whether or not it is positive disintegration depends upon a multitude of other factors. It is a problematic situation that Stonequist describes as "peculiarly conducive to thought." According to Adler, the multicultural person's ability to disintegrate and reintegrate cultural frameworks "may very well represent an afrirmation of individual identity at a higher level of social, psychological, and cultural integration." The multicultural being is therefore shaped by the tensions involved in balancing dual or multicultural afriliations and identifications.

Synthesis of the Attitudinal and Behavioral Manifestations of Multiculturality Accordine to Stonequist. Adler. Bochner, and Taft

The attitudinal, and behavioral patterns of multiculturality described by each of the four selected authors (Adler,1974; Bochner,1981; Stonequist,1935,1961; and Taft,1981) are summarized in the following sections. Their writings have been qualitatively analyzed and synthesized into five major categories: Multicultural Bnculturation; Multicultural Transitions and Identifications; Multicultural Perspectives; Multicultural Stresses; and Multicultural Mediation Tendencies. 
Multicultural Enculturation

Stonequist, Bochner, and Taft state that a multicultural identity may evolve from a monocultural one through an individual's in-depth interaction within three or more cultures and must include some assimilation of more than two cultures. According to Adler, multicultural identities are most likely to evolve where the foundations of collective cultural identity are shaken, and individuals internalize a psychoculturally diverse sense of awareness often, but not always including some cultural assimilation. Both Adler and Bochner address the possibilities of forming multicultural identities through culture learning during adulthood. Por Stonequist and Taft, multicultural assimilation usually occurs during childhood. At this stage of development relationships are formed without consciousness of racial or cultural differences, which makes assimilation more complete. Taft outlines several types of multicultural enculturation processes. The following three are relevant to this study: primary familiogenic multiculturalism type I which includes individuals born of parents having two separate cultures; primary familiogenic multiculturalism type II, which includes individuals who spent the first six years, or more, of their lives in cultures to which their parents were not native; and secondary idiogenic multiculturalism which includes individuals who's multicultural experiences began after seven years of age.

All four of the selected authors surmise that the more completely heteroculturals assimilate and try to belong to the cultural groups in which they interact. the greater are their confusion and difficulty when they find themselves excluded from a cultural group with which they identify. The growing awareness of the lines and barriers of cultural differences produces 
the characteristic stresses of the position described by Stonequist. Bochner, and Taft as culturally marginal and by Adler as afflictions of multiculturality.

\section{Multicultural Transitions and Identifications}

Each of the four selected theorists describe the multicultural person as an individual whose identitity is formulated on awareness and inclusion of culturally diverse life patterns and definitions of reality. Stonequist, and Adler further describe these individuals as never being one with any single culture, but remaining "outside" as "stranger's" in social situations. According to Bochner and Taft, multiculturals feel a need to associate with and relate to an international reference group both socially and professionally. They feel more of a sense of belonging with individuals whose experience is also international, regardless of nationality.

Frequent personal transitions and a need for growth and change are identified by all four researchers as characteristic of heterocultural individuals. Both Adler and Stonequist describe multiculturality as involving a cyclic pattern of personality development with an implicit sequence of growth. According to Adler, this cyclic process of personality disintegration and reformation leads to the development of higher levels of integration each time the cycle is repeated. Stonequist describes a sequence of marginal personality development through which assimilation without consciousness of difference occurs, followed by a gradual or acute "crisis," surrounding the recognition of difference. This leads to a metamorphosis of cultural habits and patterns during which reintegration and adjustment takes place. Thus, multiculturals are resilient and evolutionary individuals whose sequential identity development leads them to seek continuous growth and change. 
Each of the selected writers suggests that multiculturals are contertually adaptive. This means that they adapt their needs, drives, motivations and expectations to fit the contert in which they are functioning. The facility for moving in and out of conterts while maintaining some inner coherence through varieties of situations enables the multicultural to negotiate the conflicts and tensions inherent in cross cultural contacts (Adler,1974). This ability to maintain a sense of inner stability and coherence throughout these adaptations differentiates the "unsuccessful marginal," from Stonequist's successful "multicultural marginal man," or the "mediating person" described by Bochner and Taft.

\section{Multicultural Perspectives}

Each writer describes multicultural people as beings whose perceptions of the world are formulated on some sort of globalist or universalist perspective. Their "worldmindedness" identifies them with mankind as their primary reference group (Taft). Their values, which include a belief in the common unity of all peoples, are probably shared by most of mankind (Bochner). Multiculturals are "internationalists" or "citizens of the world" (Stonequist). Their identifications and loyalties transcend boundaries of nationalism, and they are committed to a vision of the world as a global community (Adler).

Adler emphasizes the multicultural's appreciation and respect for cultural differences as well as for the similarities that unite humanity. He draws a parallel between multiculturals and the great philosophers of both the East and the West in their commitment to both the universal and the particular. Adler (1974) summarizes the essence of the multicultural position in the following passage: 
What is universal about the multicultural person is his abiding commitment to the essential similarities between people everywhere. while paradoxically maintaining an equally strong commitment to their differences. (p.25)

Cultural relativism is an essential component of the multicultural perspective Bochner, Adler, and Taft describe. Bochner emphasizes this value as particularly salient in the multicultural by claiming that the more cultures one knows, the greater is one's commitment to cultural relativism. Taft states that multiculturals are likely to have a culturally-relative perspective which aids them in the acquisition of language and other sociocultural competencies, and enables them to interact in unfamiliar cultures in a relaxed manner. Adler proposes that the flexibility of multicultural persons in adapting and adjusting to great variations in cultural patterns is based on a belief in the following principles of cultural relativity: 1) every culture has it's own internal coherence, integrity, and logic; 2) all cultural systems are equally valid as variations on the human experience; 3) all persons are to some extent culturally bound. Stonequist emphasizes the ability of the multicultural to transcend the boundaries of each culture, to understand and to take the roles of distinct cultural positions, but he does not speak of valuing each of them equally. Cultural relativism is not mentioned in Stonequist's interpretation of the multicultural identity as it is in the works of Adler, Bochner, and Taft.

All four authors describe multiculturals as nonjudgemental. Because they are intrinsically aware of cultural differences in values as well as in perception and interpretation, multiculturals do not evaluate one situation in terms of another. Multicultural persons wait until they comprehend the context enveloping a situation before forming conclusions. 


\section{Multicultural Stresses}

All of the surveyed authors describe certain stresses to which individuals are particularly susceptible. These problem areas are centrallzed around issues of identity and belonging. The tensions inherent in this marginal position are profound and may be so overwhelming relative to some individual's resources that social adjustment remains out of reach (Sionequist). Each of the four authors states that these internal confticts may arise as a result of the heterocultural's intimate knowledge of diverse cultural patterns.

According to Stonequist, the essence of the marginal situation is one of partial assimilation and psychological identification with a dominant racial or cultural group without full acceptance from that group. Thus, these individuals find themselves on the margin of each society, partly in and partly out. Each of the authors concur with the premise that the pain of the marginal position lles in the attempt to identify and belong within the groups to which these heterocultural individuals are involved. The pain $\alpha$ this unfulfilled need for belonging results in the loss of their otherwise characteristic objectivity, develops a sense of detachment and indifference, and increases vulnerability and stress (Adler, Bochner, Stonequist). If heteroculturals are able to reconcile themselves with remaining strangers, they maintain their somewhat superior position of objectivity, and sympathetic understanding (Adler, Bochner, Stonequist, Taft). Adler believes the flexibility exhibited by multiculturals can disguise superficiality and avoidance of real human problems. Through this internal flexibility they may also become overwhelmed by conflicting interests due to the equal 
validity they assign to the diverse cultures, and ideologies they find appealing. Thus, multiculturals may become what Adler labels "dilletantes," or dabblers who are unable to commit to or become totally engaged in consistent endeavors such that their identitities remain in constant flux. Stonequist (1961) describes the same phenomenon, which he calls "deracine cosmopolitan." This is, as Adler's dilletante, an individual who is "culturally adrift, living on the surface of life, broken away from traditional moorings and excessively vulnerable to stimuli."

\section{Multicultural Mediation Tendencies}

The concept of multiculturality is discussed by each writer as a position that is rich with the potential for creating human beings with superior abilities for serving as bridges between cultures. An essential ingredient in each author's characterization of cultural mediators is concisely expressed by Taft:

First and foremost, the quality needed to act as a bridge between members of diverse cultures is sensitivity to the feelings of people and the ability to put oneself in their position, to construct the world as they do and to experience the action tendencies and emotions that they do: in other words, the ability to empathize with others. (p. 82)

In Taft's view, multicultural persons are able to interact in unfamiliar cultures in a relaxed manner conducive to developing and exercising the communication skills pertinent to cultural mediation. A cultural mediator facilitates communication, action, and understanding, between individuals or groups that differ with respect to language and culture. The role of the mediator involves interpreting the expressions, intentions, perceptions, and 
expectations of each cultural group to the other. Adequate performance of this intermediary role requires some knowledge of the languages and roles employed by members of each cultural group. Thus, the mediator must be able to transcend the boundaries of each culture concerned and be able to comprehend the signals used in the expression of each. Through knowledge of each culture, the mediator may be able to perceive and even anticipate possible areas of futile and frustrating attempts to com municate. Because it is essential for an individual to be flexible in switching cultural orientations in order to play the role of mediator. Taft believes that multicultural individuals are uniquely suited for this position.

Bochner's working model of a mediating person describes: "an individual who is multicultural, functions in a transnational role, has a transcultural reference group, obtains transcultural social support for his professional work, and has a social network spanning many cultures." Mediating persons are active individuals whose general purpose is to contribute to international understanding. They are translators, and good communicators who like and respect the lifestyles of each culture involved in a situation they are capable of mediating. They feel equally at home or comfortable in each.

Stonequist also states that the marginal persons whose affiliations are multicultural have a unique capacity to serve as intermediaries. They are insightful, have an attitude of objectivity, are free from local prejudices and values, develop abstract and generalized social relationships, and have a unique capacity for nearness and sympathetic understanding. These qualities of "sympathetic objectivity" facilitate the relationship of confidant and mediator. 
Adler claims that multicultural persons function superbly as intercultural mediators as they are facilitators of cross-cultural communication, and catalysts for contact between cultures. They are able to relate to a variety of conterts and environments without being totally encapsulated or totally alienated by particular situations. Multicultural people are especially well suited for positions requiring intercultural understanding, facilitation, and research.

Mediating persons need to be involved in political, intellectual and social climates that value their achievements and approve their goals, and to have a reference group against which they can evaluate their own performance. They need to be involved in work they consider meaningful and have a professional role that provides them with a reasonable degree of status ( Adler, Bochner, Tart, ).

Each of the surveyed authors describes multiculturals as individuals who are committed to making significant contributions toward improving intercultural and international understanding on both face-to-face and global levels. Multiculturals seek to establish and balance communication, they have unique capabilities to serve as intermediaries, facilitators, and synthesizers in cross-cultural conterts. 


\section{CHAPTER III}

\section{METHODOLOGY}

\section{Purpose}

This study is a preliminary exploration of specific attitudes and behavior patterns that may be characteristic of individuals who experienced primary socialization in three or more international environments. The congruence between the patterns described in the literature by Adler (1974), Bochner (1981), Stonequist (1935,1961), and Taft (1981) as typical of "culturally marginal," "culturally mediating," or "multicultural" persons, and the self-reported attitudes and behaviors of several multiculturally socialized individuals is explored.

The research proposition is that socialization involving immersion in three or more international environments is reflected in the attitudes and behaviors of the individual's experiencing these distinct cultural environments. All four of the selected researchers report that individuals experiencing primary socialization in several cultures may acquire and internalize something from each set of cultural expectations and thus develop multiple patterns of attitudinal, behavioral and communicative response. Thus, the potential arises for these individuals to become adept at cultural mediation, and synthesis of groups, as well as for being particularly vulnerable to certain stresses unique to those having had multiple cultural involvements. 
In this study heterocultural individuals are interviewed in regard to the themes implicit in the literature and their responses are analyzed to determine the extent to which they support those themes.

\section{Overview}

This is an exploratory study that utilizes the descriptive method of data collection and a qualitative method of data analysis. This exploratory research is initiated by an analysis of the literature and a synthesis of the patterns described by the selected authors as characteristic of multicultural identities. The major theoretical concepts, themes, and categories synthesized from this preliminary analysis may be found in Appendix A.

A purposive sample of interview subjects is selected through the use of a demographic screening instrument designed by the author in order to determine the candidate's eligibility for participation in the study. The criteria for subject selection are based on exposure to multiple cultural environments during the formative years as defined by Taft. The screening instrument may be found in Appendix B. The selected study group is comprised of a cross-section of multiculturally socialized men and women having wide age ranges and cultural experiences.

Subjects are interviewed according to a schedule of questions generated from the theoretical constructs reviewed earlier.

Data analysis involves coding and refining all of the research data senerated by the analysis of the selected literature and the purposive interviews. It culminates in the presentation of the salient themes surfacing as representative of the attitudes and behaviors of individuals exposed to multiple environments during their formative years. 


\section{Genecal Methods}

The methodology selected for use in this study is termed "naturalistic inquiry," which is sometimes used synonymously with "pretest," or "exploratory" research (Tucker, Weaver, \& Berryman-Fink, 1981, p. 119 ). An exploratory approach is seen as a method for generating hypotheses rather than testing them. The research data is qualitatively rather than quantitatively analyzed. When one is interested in obtaining insight into an area where there is much speculative writing and little empirical knowledge, an exploratory study is usually the most appropriate (Selltiz, Jahoda. Deutsch, \& Cook, 1960 ). It is particularly useful in the study of heteroculturality as there are many theoretical models that concern this subject, but little empirical substantiation. There is also a lack of uniformity in terminology.

Naturalistic inquiry is a descriptive method of research. Its purpose is to gather information describing events, beliefs, attitudes, values, intentions, preferences, or behaviors, directly from the individuals possessing the information (Tucker et al., 1981 ). The descriptive method of data collection is useful in this study as it purposefully allows for the subjectivity of the participants' responses, which is the primary concern of this investigation.

The research is initiated by a qualitative analysis of the patterns described by the selected authors as characteristic of multicultural identities. The results of this analysis are synthesized into five major categories containing fifty-five attitudinal and behavioral characteristics attributed to multicultural individuals. This first stage of data analysis is described by Taylor and Bogdan (1984) as the "ongoing discovery" phase. The interview 
schedule of questions is based upon the salient themes and categories that emerged from this preliminary phase of data analysis.

The oral interview format is adopted as it is recommended for its ability to allow the opportunity to identify misinterpretation, clarify inconsistency, probe for additional information, and pursue selected topics in greater depth and detail than other methods allow (Waltz, Strickland, \& Lentz, 1983, p.263). The open-ended questions comprising the oral interview schedule provide flexibility in the interview session and encourage the study participants to describe their unique experiences as fully as they wish. This leads to a great deal of very personal self-disclosure.

The number of participants in this study is limited by the in-depth nature of each interview, restrictions of cost and time, as well as by the specific criteria identifying the population of interest. The informants are purposively selected based on their experience in multiple cultural environments during their formative years. "Apart from interviewing enough people to ensure adequate representation of different types of experience, there is no simple rule for determining the number of informants who should be interviewed in an experience survey" ( Selltiz et al., 1960, p. 56). Respondents must be carefully selected, "as it is a waste of time and effort to interview people who have little competence, or little relevant experience" (p. 55).

The second phase of data analysis involves coding the interview results and refining the thematic code itself. As common themes emerge from the interview transcripts, the preliminary literary themes are sorted, collapsed and combined in order to reflect the attitudes and behaviors described by the participants themselves ( See Appendix E for the refined list of themes). For, according to Tucker, et al. (1981 p.119), it is the 
individuals' own interpretations of their worlds that are of primary interest to the exploratory researcher.

Because the methodology employed by this study involves face-toface interaction, the respondents are always aware information is being solicited. Thus, the data gathered is influenced to some degree by the subject's perceptions of the interviewer, the questions asked, the timing and the setting.

\section{Population and Subject Selection}

The population of interest to this study are adult individuals who experienced multiple international cultures during the first 18 years of their lives and were thus exposed to multiple cultural frames of reference during primary socialization. It is a population that Taft defines as being either primary familiogenically or secondary idiogenically multicultural. Taft describes two types of primary familiogenic multiculturalism. The first type includes individuals born of parents having two separate cultures. The second type includes individuals who spent the first six years of their lives in cultures to which their parents are not natively born. Secondary idiogenic multiculturals are those individuals who are exposed to multiple cultures arter seven years or age. Both primary familiogenic and secondary idiogenic multiculturals develop their fundamental perceptions, values, and beliefs, while living in different countries and having the opportunity to interact with members of several distinct cultural groups. This heterocultural population is comprised of the children of missionaries, refugees, diplomats, scholars, government and private sector employees whose primary socialization occurs in multiple cultural environments. 
The interview subjects in this study are purposively selected. Selltiz et al. (1960) suggest the use of a purposive sample of interview respondents for exploratory research when the aim is to obtain insight into an area of study rather than provide statistical measurement. Respondents must be chosen because of the likelihood that they will offer the contributions sought. A demographic screening instrument designed by the author provides uniform criteria upon which to determine the eligibility of prospective candidates for participation in this study.

Prospective interview candidates were referred to the researcher by individuals who are involved professionally or socially with internationallyoriented organizations within the Portland metropolitan area. Selected interview participants also referred other multicultural individuals as potential subjects.

The screening criteria limits the selected population according to international experience, national residency, age, and fluency in the English language. Twenty-two candidates were administered the demographic screening instrument. Nine persons qualified for participation in the study. Later, one interview transcript was deleted due to the subject's discomfort in completing the interview. The final study group consisted of eight individuals from several ethnic and national backgrounds who: lived within three or more distinct cultural environments during the first 12 years of life; engaged in continued international living through the age of 18 or older; are current residents or citizens of the United States between 21 and 45 years of age; and are fluent in the English language.

Each of the final interview participants fit within one or more of Taft's definitions of multicultural socialization. Six of the eight subjects were socialized according to Primary Familiogenic Multiculturalism Type II, which 
means they spent the first six years of life in cultures to which their parents are not native. Three of these sir subjects also fit into the category of Primary Familiogenic Multiculturalism Type I, meaning that each of their parents is from a separate culture. Two subjects are Secondary Idiogenic Multiculturals, meaning that exposure to more than one culture occurs after seven years of age. One of these subjects moved to a second cultural environment at six years of age, so technically he fits partially in each category. The other remained in her country of origin, but changed residences nine times by the time she encountered an international relocation at age seven. See Appendix $C$ for specific information concerning the study participants primary socialization. Included are the subjects parental nationalities, geographical locations, environmental settings and the dates of their births and relocations.

\section{Interview Schedule of Ouestions}

The interview schedule of questions is based upon the themes and concepts that emerged from the qualitative analysis of the literature. Suggestions for improving the clarity of the interview questions were solicited and obtained through administering the interview schedule to three pretest subjects who commented on the clarity and apparent bias in some of the questions. Their suggestions are incorporated into the schedule. The resultant interview schedule may be found in Appendix $D$.

This researcher conducted all interviews in a conversational manner guided by an open-ended interview schedule designed to elicit free-form, subjective and detailed accounts from interview participants. The fortyseven interview questions are based on the attitudinal and behavioral 
characteristics attributed to multicultural individuals contained within the major conceptual categories addressed in the selected literature.

The multicultural enculturation experiences of each participant are solicited through the first eight interview questions. Interview questions nine through fourteen and sirteen through twenty-one explore the respondents' cultural identifications and transitional characters. Questions fifteen, and twenty-two through thirty-two aim to expose the world views held by the multicultural population involved in this study. Questions thirty-three through forty concern the particular stresses exerienced by multiculturally socialized individuals. Multicultural mediation tendencies are assessed by self report in questions forty-one through forty-five of the interview schedule. This assessment is supplemented by analyzing responses to other questions throughout the interviews that indicate particular communication styles and awarenesses described by Stonequist, Adler, Bochner, and Taft as indicative of "mediating" or "intermediary" positions. Questions forty-six and forty-seven ask respondents if they wish to add additional comments regarding their multicultural upbringing to this study.

\section{Validity and Reliability}

As Rist (1977) explains, quantitative researchers emphasize reliability and replicability in their research, while qualitative researchers emphasize validity. Deutscher (1973, p.41) claims that reliability has been over emphasized in social research with the frequent consequence of learning a great deal about how to apply maximum precision in the pursuit of courses that may be incorrect. 
Taylor and Bogdan (1984) describe qualitative studies as demanding. though not necessarily standardized, pieces of systematic research that are designed to ensure a close fit between the data and what people say and do. By listening to people speak openly, the qualitative researcher obtains first hand knowledge of social phenomena unfiltered through operational definitions and rating scales ( p. 7).

Qualitative research is an inductive way of approaching the empirical world. It is exploratory by nature. Researchers are concerned with developing concepts, insights and understandings from patterns in the data rather than quantitatively assessing theories, or hypotheses (Taylor and Bogdan, 1984, p. 5). Research is initiated using vaguely formulated research questions. Through qualitative research coding, interpretations of the data are developed and refined. Initial themes, concepts, ideas, and propositions are expanded, refined, discarded or fully developed. Thus, internally-valid themes and hypotheses emerge from the analyzed data.

The interview schedule of questions used in this study is inductively designed using normal qualitative research procedures. The forty-seven open-ended questions arose from the qualitative analysis of the propositions and models presented by four prominent researchers of heteroculturality.

Several generalized questions pertaining to each conceptual category are included in the interview schedule in order to assure covering each issue completely, to minimize the amount of misinterpretation, and to incorporate cross checks on the subjective information given by the subjects. The cross checks are designed to enable the researcher to examine the consistency of the subjects' statements and to elicit a more or less honest view of how informants actually view themselves and their international experiences. 
However, the value of the research is not dependent upon objectivity on the part of the interview subject. Rather, as stated by Shaw (1931) in his description of qualitatively analyzing an interview:

It is desired that his story will reflect his own personal attitudes and interpretations. Thus, rationalizations, fabrications, prejudices, and exaggerations are quite as valuable as objective descriptions. (p.3)

\section{Procedures}

This researcher conducted all aspects of this exploratory study. The interview participants are purposively selected through a demographic screening process. The criteria for subject selection are based on the interview candidates' exposure to multiple cultural environments during their formative years as defined by Taft. The chosen study group is comprised of a cross-section of multiculturally socialized men and women having wide age ranges and cultural experiences.

Participants are aware that this research is to be used for a master's degree thesis and is available to them upon request. The anonymity of the interview subjects is assured.

All interviews are conducted in the homes of either the interviewees or the researcher, whichever the interview participant prefers. This is done in order to maximize each participant's comfort level and to minimize inconsistency in the interview procedures. The interview sessions last from one to four hours depending on the disposition and schedule of the interview subject. All interviews are tape recorded with the informant's permission and transcribed. 


\section{Data Analysis}

According to Taylor and Bogdan (1984) when researchers code and analyze their own data they are enabled to continually refine their interpretations and thus gain a deeper understanding of what they have studied. First-hand experience with informants helps researchers make sense out of the data. The data analysis procedures this study utilizes entail three distinct phases outlined by Taylor and Bogdan (1984). The first is an ongoing discovery phase which involves identifying and developing themes and concepts. The second phase, which occurs after the data have been collected, involves coding the data and refining the researcher's understanding of the subject matter. In the final phase, the researcher attempts to discount her rindings.

The "ongoing discovery" phase of data analysis in this study is two fold. The preliminary step involves the identification of behavioral. emotional, and communicative descriptions of multicultural identities presented in the selected literature. The second step involves synthesizing these concepts into major themes and categorizing them according to the most prominent issues discussed by each of the selected authors. The literary synthesis reveals five major categories addressed by each of the surveyed writers. These are: 1) Multicultural Enculturation; 2) Multicultural Transitions and Identifications; 3) Multicultural Perspectives; 4) Multicultural Stresses; and 5) Multicultural Mediation Tendencies. Within these categories, fifty-five salient themes are identified (See Appendix A for a listing of these themes). 
The second phase of data analysis occurs after the interview data have been collected. It involves reading and rereading the interview transcripts, coding the interview results and refining the thematic code itself. As common themes emerge from the interview transcripts, the themes from the literature are sorted, combined, and synthesized to reflect the attitudes and behaviors described by the participants themselves. Themes from the literature that are not reflective of the interview responses are also noted (See Appendir $\mathrm{E}$ for the refined list of themes).

The final phase of the qualitative analysis involves attempts to discount the research findings by describing the study conditions contextually. The results of this phase of data analysis are often referred to as research limitations. The assessment of the credibility of the data collection and interpretation is discussed under Limitations in Chapter V. 


\section{CHAPTER IV}

\section{RESULTS AND DISCUSSION}

The following discussion is an in-depth presentation of the research findings. It is concerned with the congruence between the descriptive themes generated by the first and second phases of the data analysis. The themes that appeared consistently throughout the interview transcripts are considered the most reflective of the behaviors and attitudes of the multiculturally socialized study group. The most salient themes are discussed in depth and illustrated with quotations from the interview data. Literary themes not reflected by the study participants, or mentioned by only a few respondents are also noted. All of the themes are reported in this chapter under the categories of: Multicultural Enculturation; Multicultural Transitions and Identifications; Multicultural Perspectives; Multicultural Stresses; and Multicultural Mediation Tendencies.

\section{Multicultural Enculturation}

Three major theoretical positions describing heterocultural identity formation espoused by the selected authors emerged from the analysis of the enculturation experiences described by the interview participants. These are: 1) the foundations of cultural identity are shaken, whereby individuals are exposed to and interact in multiple cultures to the extent that they lose their sense of identification with one cultural reality and develop a psychoculturally diverse sense of awareness (Adler); 2) partial assimilation 
of cultures, whereby individuals incorporate attitudes, behaviors, and communication patterns characteristic of each culture (Stonequist, Bochner, Taft); and 3) crisis of discovering cultural differences, whereby early relationships occur without awareness of cultural difference, and later become a source of inner conflict due to identification with each group (Stonequist, Bochner, Taft). Even though partial assimilation was not claimed by seven or more respondents, it is reported here due to its significance in the study of heteroculturality.

1) The foundations of cultural identity are shaken.

All eight subjects exhibited feelings of having the foundations of their cultural identities shaken by experiencing distinct cultural realities. Through this exposure to and interaction in other ways of life, they develop a psychoculturally diverse sense of awareness and an inability to identify with one cultural reality. Following are a few responses that typify the expressions of this feeling:

JP: I think 1 became a part of each and every one of those cultures. Not entirely, not entirely as to the extent of losing my own identity. But then, I don't know what identity is really, with relationship to a culture. It's hard for me to explain because I never thought of myself as very typically a part of any one culture. So, it would be different if I say, well here I come, and I love Chilean music and I love Chilean food, and I breath Chilean, and I defecate Chilean and everything Chilean, but I don't. See? And that's why it's difficult to give you a clear definition of what I felt. Never, never accepted by any particular group 100x, but yet never feeling that I was excluded in any part.

PE: I really didn't identify with anyone. I guess I had a hard time knowing eractly who I was, what nationality I was. This is the first time I realized I was a Canadian. I didn't know the provinces or the history. But what did it mean to be Canadian? I didn't know if I was Canadian or not, you just put on the language or accent and interacted. How would they know what you are? So the whole idea of nationalism or patriotism is a question. 
SP: I feel really transient and unsure of where to go and what to call home, when people ask me where I'm from. That makes me want to 80 abroad more. I don't even know if I ever want to settle either. . . I feel culturally ignorant of the American culture in some ways too. Like some things people would all know how to do and what to say and how to act in certain situations in the states, Americans would, and I wouldn't know what to do and I'd feel, in that way I'd feel excluded as well.

2) Partial assimilation of cultures.

Partial assimilation of cultures was indicated by the degree to which individuals reported feeling that they had incorporated the attitudes, behaviors, and communication patterns characteristic of each culture. All eight respondents reported developing conversational fluency in the languages spoken in each country they lived in, as well as having daily contact and some significant relationships with host nationals. This level of involvement did not indicate feelings of cultural assimilation. Five of the interviewees spoke of internalizing the cultures in which they interacted, and three respondents maintained that whereas they felt they had been profoundly effected by their international sojourns, they did not feel they had become "part of" the cultures they encountered. The following quotes from SP and LH are indicative of the non-assimilative position:

SP: I feel like I've really become enriched by the cultures that I've lived in. Being part of the culture, I think I took a part with me. I don't know if I was a part contributing to the culture. We did do certain things and participated in certain events with the people of each country in certain areas, but I never felt completely immersed in the culture.

LH: I, I really, I'm very cynical about saying that, you know, somehow I assimilated the culture; I don't think I did, in any of them. Maybe at a -when I was very young, probably more than at any other time. 
Five respondents felt they had incorporated cultural attitudes, values, behaviors, and communication patterns from the cultures they lived in as their own. MJ discussed his adoption of Latin American values and attitudes concerning time and fate. PE recognized his internalization of Pakistani behaviors and attitudes involving sex roles. Both BW and PL discussed differences in non-verbal communication patterns that they had each assimilated from Laos and Spain respectively. Eramples of the cultural patterns incorporated are reflected in the following interview passages:

M]: Sometimes I'm one way, like being on time, and other times I'm not. So, I think I vary. Sometimes I'm alot more Latin, and sometimes I'm more Anglo in those habits and patterns. . . I probably have more of a, somewhat of a Latin value when it comes to letting things slide, or just not getting too bent out of shape when things don't work right.

PE: I have a sense that, how to say this, um, Pakistani culture is very male oriented and pretty aggressive in some ways, and I think that has been one of my adjustment problems in life in North America. And I think when I came back here, I had internalized certain aspects of that culture that are not compatible with the culture here. I can see this really easily whenI look at South Indians, Pakistanis and Indians who live in North A merica now who have adjustment problems here. I can almost see some of my own attributes mirrored in these people. But at some point I realized that those qualities weren't compatible with life here, and I had to deal with that, I had to say, "well I'm stuck here, well I live here," or whatever and I can't even give specifics, I just know this went on in my mind. That sometimes I would relate to something and I think Iwas relating to it as a Pakistani, almost, but it didn't fit here. So that was even more confusing, and made me feel even less comfortable. But now I think I'm getting less -- reacting less and less like one.

BW: In Laos, pointing your foot, or having your foot point at someone is very rude. I find myself in this country, if somebody's sitting there with their foot pointing at me, I'll feel this stirring up of anger, and I'll go . "Okay Becky, now what is it you're being angry about." And I'll 80, "his foot is pointing at me," and I'll go, "but he's an American, so it's okay." You know, that type of thing. 
PL: I was fluent in Spanish, I still am if I'm around Spanish-speaking people now, after about, oh, about a week I even begin to dream in Spanish. I become much more expansive with my hands. I tend to speak with my hands anyway, but then it's much more, when I catch myself in a mirror or something I, it's much more dramatic, than I nor mally do. -- I slow down. I mean I just sort of feel, like I'm slowing down -- internally I'm becoming more quiet. I don't think my speech slows because Spanish is a very quick language, but -- I don't quite know how, but I do.

3) Crisis of discovering cultural differences.

Though the extent of each person's "crisis" of realization differed significantly, all eight subjects responded affirmatively with an account of an experience in their lives when they became aware of differences between themselves and another society or segment of society. Five of the interviewees mentioned a period of their lives when they were not at all aware of cultural differences. Three subjects were aware of cultural differences from an early age.

The statements made by $\mathrm{MJ}$ and $\mathrm{BW}$ are representative of the five respondents who formed early relationships without awareness of cultural differences. These individuals were effected by partially assimilating each culture at an early age and later discovering the differences.

BW: I was at an age where basically you didn't notice the customs, the differences in customs, you just sort of absorbed them without really noticing well this is different or that's a different thought, or "Oh, this is the way it's done!" There wasn't alot of reflection at the ages of seven, eight nine and ten, you just participate. It's not until you get back here that you discover that you've got alot of thoughts and feelings and stuff like that that don't fit in here.

M]: I can remember -- an incident in Panama in which 1 was with another American child who talked about Panamanians in a negative way, basically in sort of a racist way. And that does stand out in my mind as I was surprised that that was a part of him, and that did sort of confuse me. I remember talking to my parents about it, and about what the Panamanians 
were and what I was, and what this other child was. That was probably my first memory about differences .... It just took me, I think a little while to understand that this person even grouped Panamanians as a group, I mean that looked at them as "they." And that was my first perception of a "we/they" scenario.

Three interviewees were aware of cultural differences at the outset of their cross-cultural involvements. Each interviewee described the "crises" surrounding the recognition of differing cultural realities as profoundly affecting their present day life patterns, attitudes and behaviors.

SP: I can probably remember the strongest sense of difference in Zaire because the people were so different there.... One thing that I really felt was that no matter how much I wanted to be a friend of a Zairois, or no matter how much it was mutual, I felt we could never overcome our differences.

JS: I think when I was in Chile I began to get a sense of that because we had servants and I became very class conscious. Intense awareness of difference. ... I was experiencing them more than my own culture and I didn't even know my furious resistance .. . I began to identify more with the Latin culture in Panama and see myself as that energy. . . Before that? A definite resistance. I hated the countries 1 lived in. 1 identified with America definitely. Maybe there was some conditioning to do that. Even though there was always "be nice" there was never "become like this culture."

LH: I think that in a way I had a sense that I was different because I can remember-- people teasing me and my sister both -- they'd speak some sort of garbled attempt at Chinese, basically teasing us because we had slanted eyes, and that kind of thing. And, I guess I don't really remember running into that anywhere except in the States. Just kind of disturbing.

The enculturation experiences described by the interview participants involved having the foundations of their cultural identities shaken, as described by Adler. Their exposure to and interaction in multiple cultures excluded each of them from identification with one cultural reality and led 
them to develop a psychoculturally diverse sense of awareness. Although the entire study group developed language skills, participated in cultural activities, and developed friendships in the countries they lived in, only five participants felt they had partially assimilated the cultures in which they lived. The "crises" experienced by JS, SP, and LH may have prevented them from feeling they had assimilated the cultures to which they were exposed during primary socialization. The crisis of discovering cultural differences provided some inner conflict for each interviewee. This was sometimes attributed to identification with each group as proposed by Stonequist, Bochner, and Taft, and sometimes connected to the inability to identify with any group as suggested by all four selected authors.

\section{Multicultural Transitions and Identifications}

The interview results reveal a highly mobile and transitional group of individuals who see themselves largely as outsiders and strangers in group situations. The following themes were salient in the interview data: 4) development of an international reference group, or a sense of belonging with individuals whose experience is also international regardless of nationality; 5) frequent personal transitions, a fluid identity pattern predicated on a need for change; 6) contextual adaptability, the ability to make perceptual adaptations as one moves in and out of conterts; and 7) the ability to maintain a sense of inner coherence and stability through one's situational and contertual adaptations.

All eight interview participants mentioned relating more comfortably with other internationally experienced persons than with people who have had no overseas experience. Three of them emphasized that the only groups 
within which they felt they belonged were comprised of internationallyexperienced individuals. Following are responses reflecting a cross-section of the feelings expressed:

BW: Sometimes I'll find myself in a situation responding to somebody else like, "Oh Wow! there you are!" and midway through the conversation I'll realize they're English, or German, or French, or Lao, but I will have felt connected and felt a part of that. Like, "Oh God! I'm home, this is where I belong. This is it! This is it!" And realize that often times that person is a foreigner to this country. But it's like I can take on the personality of their country. I can feel French. I can feel German. I can feel Lao and Thai, but I have trouble here feeling American. Does that make sense? I've never actually formed a friendship with someone that hasn't lived overseas -- I'm not sure why that is either. It's almost as though there's a problem with communication.

MJ: Well, I mean, sometimes it's hard to, there's just damn few people I can relate to um -- um -- extensively. And so, I wonder if those things are connected. You know I can relate to a lot of different people on a lot of different levels, but really very, very few people thoroughly. People who I know that they have the same perceptions and that they're coming from the same place, in a very general sense.

\section{Q: Do you seek those people?}

MJ: Not really. I mean, I mean, how often do you run into them. I don't do back flips for them. I don't run an ad in the personal classified for them. I mean, you know, it's nice when I run into them. I can't think of when or how often that's happened. But I've had the experience of running into people like that and then hitting it off you know, and knowing they have the same perceptions, and it's based upon their, the same kinds of experiences. So in essence it's identifying that, oh yeah, they're of that same group, and that's an identity thing.

SP. I'm always interested in what's going on abroad, and I'm always interested to talk to international students. Sometimes I feel more at home with them than I do with Americans, because I don't feel truly American, well, I don't feel truly U.S. American, I don't know. I think that I look at things differently than some Americans do because I think that some Americans are really narrow-minded and think of only the U.S. or themselves. 
JP: I notice that I feel more comfortable among people wherever I went that were of more liberal views -- people that identified with certain moral ethics. That's the people that I felt more comfortable with, and I found those kind of people everywhere. And that is almost a common denominator, regardless of their cultures or their countries that they come from, people that are concerned with what's happening with the world, and people that can go further than national frontiers, and chauvinistic attitudes about territorial possessions.

\section{5) Frequent personal transitions.}

All eight participants reflected transitional life patterns. Following are responses indicating this fluidity of lifestyles:

SP: Changes are as much a part of my life as things going smoothly. I don't look on change as something that breaks up my life 's routine, 1 just look at it as very much an intrinsic part of it.... When things stay pretty static, I get itchy. I get pretty restless.

LH: My latest philosophy about life is that I am created in every relationship, in every moment, I am created because I'm having a relationship with somebody. So, I have a very dynamic sense of myself, as in those terms I guess, at this very moment -- we are both being created by having this talk, or by having this relationship right now.

JS: I know I'm like that today. I'm never where I am. I'm always ready to leave, always ready to escape and 80 on to the next place. Its a way of life and I recognize it as such and its the only way I know. Get away, go into something new.

PE: The job I'm doing now is the best job l've ever had and if anything it's distinguished by high pressure and lots of changes -- location work, things changing ... it's very much that sort of crisis management. I never thought to say that's what I like and want from life is crisis -- but the job in itself-- if that's how it's characterized, I mean it is the best job I've ever had.

Q: Do you see yourself as frequently undergoing personal transitions?

MJ: Definitely.

LH: I think life is one big transition. 
BW: I have what I guess I would call many enlightenments.

JP: Everyday.

Q: What if any occupational transitions have you made in the past decade?

MJ: Christ! You want me to list 'em?

6) Contertual adaptability; and 7) Maintainence of inner coherence and stability throughout contertual and situational changes.

Each of the eight interview subjects described themselves as flexible and adaptable to contertual and situational changes. Seven informants indicated the ability to maintain some inner coherence throughout the varied situations and contexts in which they interact. The quotes from JP and SP express the positions of sir individuals who directly expressed having a sense of inner stability, or an integral core that does not fluctuate with the surface adaptations with which they accommodate to each new experience. LH maintains a sense of self and copes with the frequency of cultural adaptation by emphasizing her outsider position and identifying herself as an observer.

JP: I have never been consistent or stable. That's what makes me unique. I think that truthfully, there's a base deep inside of me that is very consistent, however. I have atways been subject and I have always wanted to be subject to change, and to allow, I want to allow my surroundings to influence me, you know, I'm like a sponge. I allow my environment to totally penetrate me, and I guess that's why I always feel a part of everywhere I go. Because I allow myself to be inundated by the forms and shapes, odors, colors, you know. And so I just suck all that in, without modifying the base which is pretty stable.

SP. I have certain ways that I think and ways that I act that are pretty much habits, and stable, but when I go to a different country -- I have to compromise between the culture and the way I act if there's a 
problem. I think it's a matter of adapting. You have to change if it's there. If you need to change, you make a change. You have to adapt, but I feel there's a certain pattern of behavior that I would follow and I would adapt as necessary.

LH: l'm pretty open, and if something is new to me -- if there's something that I'm not sure about, I'll wait, I'll ... try not to make the first move or, for example 1 tend to observe a lot, in order to avoid making, like, blatant faur pas, or whatever, as far as cultural mistakes 80, but I think part of being a foreign service kid is that, because you're not really a part, you're sort of displaced and put in this other country, and yet you're not allowed to actually get that involved in it, you tend to become very much a spectator, more an observer of things and not really get involved, like jump into things. At least that's, that's been my experience for the most part. And I still do that, I still, you know, do a lot of just sort of standing on the side, and watching before I get involved.

One subject stated that there was no inner stability that gave coherence to her contertual adaptations, each transition was a complete change:

JS: They can't keep up with how many people I become and how wholeheartedly I commit to those new people that I am. My only consistency is inconsistency. My most stable part of me is the fact that I'm going to change.... I change and I'm willing to let 80 of something that I'm adamant about one year, I'm totally grown out of the next year. I don't even know why I was into whatever I was into. It just doesn't have anything to do with me.

The interviewed multicultural persons appear to have developed an intrinsic knowledge of differing cultural realities through their exposure to varied cultural milieur during their formative years. The people with whom they relate the best are other individuals whose frame of reference is also international. They see themselves as strangers accustomed to change and transition as a way of life. The repeated changes in social and environmental situations have made them feel acutely aware of the need to adapt to each event. Thus, as each of the selected authors surmise, these individuals are continually involved in maintaining a balance between establishing their 
own personal boundaries and simultaneously releasing these boundaries as they engage in meaningful interactions. The ability to maintain a sense of balance and inner consistency throughout their adaptations and changes, was discussed by seven of the interviewees, with one of them describing herself as adapting to new events by remaining outside, watching and observing before engaging. Only one of the persons interviewed spoke of experiencing total identity transformations. A lack of inner stability was discussed by both Adler and Stonequist in their discussions of heterocultural stresses. This movement from experience to experience without committing oneself or one's values was described as "dilletantism" by Adler and as "deracine cosmopolitan" by Stonequist. It is mentioned here as it is a function of multicultural transitions and was demonstrated by only one respondent, thus cannot be included as a difficulty commonly experienced among the study group.

Cyclic patterns of personality development were described in the literature as characteristic of multiculturality by both Stonequist and Adler. Each of them described cycles of crisis, disintegration, and reintegration at a higher level. Thus, each of them claim that repeated cultural transitions lead to the development of evolutionary beings. Although a few respondents described their transitions as evolutionary, this theme did not appear frequently enough in the data to be characteristic of the group.

\section{Multicultural Perspectives}

The value systems of the participants involved in this study exhibited a high level of congruency with the following themes described as characteristic of multicultural individuals: 8) internationalism, or 
worldmindedness, a sense of being a "citizen of the world" in which loyalties are to humankind rather than to separate nations (Stonequist, Adler, Bochner, Tart); 9) cultural relativism, or the recognition that each culture is equally valid in that it has its own internal coherence and integrity (Adler, Bochner, Taft); 10) non-judgementalness, or not judging one situation in terms of another, but suspending judgement until the context enveloping the situation is understood (Stonequist, Adler, Bochner, Taft); and 11) globalism, or a universalistic perspective inclusive of a commitment to the fundamental unity of mankind (Stonequist, Adler, Bochner, Taft);

8) Internationalism, or worldmindedness.

A feeling of internationalism, or being more a part of a world community than part of any specific nation was reported by seven out of eight respondents. The interviewees' levels of commitment to this principle are discussed under career goals in the section titled Multicultural Mediation Tendencies. Response patterns are exemplified by the following passages:

PE: I'm not an advocate of nationalism -- instead of segregating cultures and groups of people -- it's important to mingle people, cultures, basically to share and learn, and more than that, to participate in each other's cultures.... That, to me is what life's all about.... I don't have any patriotic loyalty. Also, I don't like what's been done in the name of patriotism.

JP: [International experience] has given me a certain overview of what the world community is like, and has accentuated the abberation that national frontiers are.

JS: I do not feel particularly, attached to living here, don't feel total national devotion to this country. I could just as easily embrace a European country. I feel like I have a sense of feeling at home wherever I am despite seeing the pros and cons of a country. Being internationally based, I'm not restricted to any country. I would feel okay about living in alot of places. I always want the ability to move on. 
One individual felt a greater sense of identification and loyalty to the United States, her country of origin, than to internationalism.

PL: When we lived in Europe, I have nothing but real positive memories of it, but I always knew I was an American, and my parents, it was real important to them, that I represent our country. They, one of the things that they would tell me, a lot, would be that I might be the only A merican that this German or this Spanish. . person would meet, and it was real important that 1 represent our country well. So I always felt like an American. I didn't lose sight of that, ever. So I think when I think about going back and living, overseas, to me it doesn't feel permanent, because I'm an American. I mean I have that sort of attitude, well, I'm an American, and, it would be hard for me to think about living in Europe, as a permanent place ... perhaps it would be different, if $I$, married someone, who was from another culture. Then it might be easier, but, I didn't, and so I haven't thought about it in that way.

9) Cultural relativism.

Each one of the eight informants demonstrated having culturally relative beliefs. Each of them made statements indicating that they recognize each culture as equally valid. Following are a few ezamples of these statements:

MJ: I look at things anthropologically in a sense of: All cultures are right, basically, intrinsically. They have rights. One is not better than another.

SP: Being in different countries and seeing different governments work, and seeing different things work for them, are all different. There's no right way. Certain people are used to certain things.

LH: My cross-cultural experiences have made me more sensitive to the fact that other values are just as valid as western values, and if people act a certain way, and I can't understand it, I'm less likely to condemn it because they might have other reasons for it that I'm not aware of. 
10) Non-judgementalness.

Not judging one situation in terms of another, but suspending judgement until the contert enveloping the situation is understood was exhibited by all eight of the interview subjects:

BW: I have trouble getting angry with people without first trying to figure out why they did it because there might be a reason they did whatever it was that upset me. A perfectly logical reason based on concepts or past experience where they weren't deliberately setting out to offend me. So. I just spend alot of time trying to figure out why people do the things they do, and what brought them to it. And, I think that's based on having lived overseas.

JP: I have this gut feeling at an emotional level and then I have to find more of the facts in order to approve or disapprove. Some things that on the surface seem unacceptable, then when you understand them, perhaps they become more acceptable.

JS: I go very much by the relativity rule, Einsteinian rule of relativity, relative to that situation and particular set of circumstances therefore my morals are pretty malleable and sometimes pretty shocking but I try to be as non-judgmental or rigid as possible because $I$ believe that morals are confusing and based on false impressions of reality, based on social expectation therefore I try not to relate too much to them except as how I'm effecting others and then try to effect others in a positive way, but then its relative. I mean, what is positive?

11) Globalism, and universalistic commitment to the fundamental unity of all peoples (Stonequist, Adler, Bochner, Taft).

Seven of the eight respondents expressed a commitment to the fundamental similarities that unify all peoples. They express the importance of looking beyond surface differences to reach for the common bonds that unify humanity that lie beneath the variations in cultural systems .

$\mathrm{PE}$ : One of the most important things l've learned is that no matter how different, backwards, simple, or sophisticated and glamorous a person looks, it doesn't matter what cultural context they are in, they obviously 
have all the same emotions that I have. They pain as much, they hurt as much, they have aspirations. . and I think that the more I travel, the more it just reinforces that everybody has the same feelings under the surface differences.

BW: Living in different countries has certainly given me a much broader understanding for human nature, realizing that people are very similar even in spite of cultural differences, and made me much more tolerant of other people's beliefs about everything.

JP: The experience has shaped my understanding of people all over the world. ... I tend to look at them a little more as people, as individuals. . I feel that looking at groups as ethnic groups will lead you to generalizations, that lead, dangerously to, come very close to prejudices.

It disturbs me how people want to accentuate differences in cultures rather than try to find similarities that perhaps could bridge and bring closer together the human family... People are very different underneath, and for this reason it is important to think about what kinds of things can be done in order to get people to work together.

One out of the eight interview subjects emphasized the importance of the recognition of cultural differences in order to enhance communication and understanding:

SP: People should pay more attention to the cuitural differences, to the culture they're interacting in. When you have two different cultures interacting you should pay attention to the differences and how to communicate through those differences, how to communicate through the cultures. I think people living abroad should be more aware.

Questions concerning the perspectives of the study group revealed four salient conceptual themes. All eight interview participants expressed having beliefs that reflected cultural relativism and non-judgementalness. These were very important themes that were emphasized throughout the interview discussions. Seven interviewees expressed having a sense of internationalism. They place a greater value on loyalty to humanity and world citizenship than on national allegiance to any single country. Only one 
person felt that she was first and foremost an American. Even so, she places a great deal of importance on having her children grow up bi- or multilingually and interacting within inter-ethnic and international communities.

Seven informants are dedicated to the globalist perspective that emphasizes recognition of the fundamental similarities that unite humankind. One respondent feels that it is of primary importance to seek and understand cultural differences and not assume similarities in value systems and communication patterns. She considers the major source of cross-cultural difficulties to be making assumptions based on a lack of awareness of cultural differences.

Adler describes the essence of the multicultural position as one of paradorical commitment to both the similarities that unite all peoples across cultures, as well as to the recognition and respect of cultural diversity. The total commitment of each of the interviewees to cultural relativism is indicative of this position. However, support of this paradorical commitment to both the similarities and differences among cultural groups is not clearly evident in the interview data.

\section{Multicultural Stresses}

The major stress factors addressed by the interview participants were similar to the following theoretical issues discussed by each of the surveyed authors: 12) lack of belonging, or feeling like a stranger that is outside most groups, and does not belong completely to any culture; 13) identity issues related to socialization in multiple cultural environments; 14) detachment, aloofness and indifference stemming from an inability to feel part of a group. 
12) Lack of belonging.

All eight respondents expressed feeling a lack of belonging in any culture, however their attitudes varied as to how they evaluated this experience in terms of their own lives. Not belonging was perhaps the most prominant issue discussed in each interview.

MJ: Well, I always knew I was a foreigner. Intrinsically, in certain ways of expression, in certain cultural parameters. There's just certain things that I perceive one way or a couple of different ways that people here wouldn't understand. And, it's the same there. It's the same in other countries, when you're a foreigner. ... it leaves me wondering about never feeling like I'm completely from one place. That sense of belonging, of being entirely American, or entirely Latin. Sometimes I think it may contribute to feelings of being a loner, not a joiner, -- not so much one of the group. I mean I have a sense of belonging to different groups, but not entirely, like people out in Goldendale, born and bred of the old families... I can draw the same analogy to people in Paraguay, born and bred of the old families. Those might be disadvantages, but I've always felt that those disadvantages have been far outweighed by what I perceive as the advantages.

SP: I feel like I don't belong anywhere in the States. .. I I feel really transient, and unsure of where to $\mathrm{go}$ and what to call home when people ask me where I'm from. That makes me want to go abroad more. I don't even know if I ever want to settle either. That's the kind of exclusion I would say. And I feel culturally ignorant of the American culture in some ways too.

PL: I don't have very many close friends -- and I think part of that has to do with living -- in a bunch of different places.

JS: I never quite fit into the Latin culture or the American culture and to this day I feel very displaced. I'm not surprized anymore. I guess I'm used to it, but I always have this sense of alienation despite whatever culture, very often with the sense of not belonging.

JP: I always felt I had the ability to adapt where ever I was, and even though maybe people saw me as different... I didn't feel left out because of it. I felt that I had the ability to deal with them on an equal basis. No, I didn't feel English, but I felt as good as the English. No, I didn't feel English, but then again, I didn't feel Spanish either, or Latin American, or French, or nothing. I just, I don't think I truly had a deep ethnic sense of belonging 
when I was growing up. In other words, I could eat Yorkshire pudding without longing for beans.

PE: The first year I was back, I went to the University in Canada and I felt, "What in hell am I doing here?" I just couldn't get along. I didn't, it went on for a long time. I got relatively comfortable, enough to get through school. But, I always felt that life was gonna start up again sometime soon when I got out of here. . I don't think I ever completely got out of it. Quite frankly, my life now, my wife and I both share this in many ways. Were not very amenable to this style of life here, and we've prety well admitted to our shortcoming, that is the inability to get along with the status quo. We've pretty well accepted that one of the possible solutions is escapism, and I think that's basically what we've decided to do.

LH: $I$, in every school that I've ever gone to, if there have been groups I've never really been part of them. I've always sort of been, uh, outside of these groups and known people in the groups, each on some kind of a oneon-one basis, but never been associated with them, as they belonged to that group.

13) Identity issues.

None of the respondents were without questions concerning their cultural identities. The significance of this issue was notable for each of them. The following types of responses were given regarding identity issues:

JS: Not confusion anymore. I have just learned to embrace the fact that I am myriad peoples. I'm schizophrenic.

M]: I think I gave up on it. I mean I kind of know I don't feel entirely American. I know that's not there for me. I don't feel Latin. That's not there for me. So, I pretty much figured it out. I don't have a strong identity.

LH: People have a tendency to try to put a label on somebody. It makes it easier on them to say, well this person is this and this person is white or -- middle class, or -- an intellectual or whatever -- and just because 1 have two nationalities and two races and I've lived all over the place I can't even deal with questions like "Where are you from?" I just 
don't know what to say because in that sense, I don't really know where I'm from. I don't have a sense of being from somewhere or another.

JP: What is identifying? I can blend in with any culture, yet I am a part of none. I am a person without an identity and without a country because everything within my life experiences is mixed and blended so I can't identify $100 x$ with any group, nor can I shed any of the vestiges of cultural heritage which I have acquired. I belong every place and no place. Geographical barriers become more and more painful. I wish we would all love one another... yet, that isn't possible. What happens to me? I become like a dangerous bridge that no one wants to cross.

14) Detachment, aloofness and indifference.

When interviewees were asked to describe their tendencies toward intimacy or detachment in their relationships to other people, there was a variation of response. Six individuals spoke of feeling detachment, aloofness and indifference with regard to groups as described in the literature. The following passages exemplify their feelings:

M): Maybe I don't like to think of myself as aloof. I don't like to give people that kind of impression, but internally, inside myself, I often feel like I'm detached, like I'm not totally one of the group kind of thing.

SP: II feel] probably more detached, not as close as I have been in the past to other people abroad.... I don't feel like I have any close friends here, like I have in the past, and I really feel a lack of it -- the feeling has gotten better, although I still feel like I don't really belong in the States. I just wonder if it's my aloofness, or it's my values, or myself.

BW: I find that I tell different people -- different things. That I segregate my life out, like, there's a lot of people here in the states that since I came back, that think they know me, and they don't, because there's a lot of myself I haven't shared with them because they would never understand it. And I've spent years trying to explain things that people haven't understood and I find when I'm with these people I shut this part of myself off. . you know though, when you continually just shut a large section of yourself off like that, or you monitor what you say all the time, or people look at you funny when you take delight or joy in something, a part of you 
dies, a little bit, you know, with that. Each time -- you can sort of -- feel a twinge.

Two interviewees felt that they were not indifferent or aloof, but felt very much interested in developing strong, meaningful relationships within the groups with which they became involved. However, they were troubled by the lack of reciprocity in the relationships they attempted to establish. One of them spoke of encountering a reluctance to form deep, non-superficial friendships.

JS: I think I'm intimate with whomever I do get involved with and I don't settle for mediocrity. 1 go for pretty deep relationships no matter with whom and I think alot of people find it difficult to deal with me because I don't settle for the mediocre, superficial. I 80 for the deep stuff and alot of people can't deal with that within themselves or from another.

The other found a lack of willingness on the part of Americans within the United States to explore relationships. Similar statements concerning attempted intimacy within monocultural US groups were made by the five interview subjects who described themselves as having developed a sense of detachment from these groups.

PL: I'm real gregarious, and, I don't think it's so much me, as I think it is other people. Which is not a very nice thing to say, maybe not true. When you're in the military, and you move around a lot, you have to make friends fast, because if you don't make friends fast, you're not gonna have any friends, because people come and go, very quickly. I'm very willing to make friends with people, but A mericans don't tend to do that very easily, I don't think. I don't think Americans do much exploring. And they don't explore much in relationships, maybe that's not true for everybody, but -I'm not discontented. I mean, I did a lot of stuff by myself when I was a child, and I do a lot of stuff by myself now.

Only one interview subject described himself as very intimately involved with other people and not feeling aloofness $o r$ indifference. 
JP: I feel very close to people that I choose to be close with because I'm interested. And regardless of their origin, if I'm interested in them as people, generally I'm very close.

The preceeding interview passages illustrate the following theoretical suppositions with which all of the selected authors concur: The pain of the "between-culture" position is attributable to the heteroculturals' attempts to lose their stranger status and to feel a sense of belonging within the groups with which they become involved. It is the discomfort of their unfulfilled needs for belonging and identification that result in detachment and indifference. The ability to reconcile themselves with their position as "strangers" would enable them to appreciate their somewhat superior positions of objectivity and sympathetic understanding, and feel contented with their positions as confidants.

Seven of the respondents described themselves as susceptible to the stresses and vulnerabilities associated with non-identification and lack of belonging. However, none of the $\mathrm{m}$ attributed their feelings of alienation to being excluded from groups with which they identified as is theorized by Stonequist. Their difficulties with groups stemmed from their own inabilities to identify with them, thus, they excluded themselves from group membership. One respondent described himself as comfortable with his outsider position as well as his ability to feel close to others.

Excessive internal flexibility and vulnerability to stimuli, as well as a tendency to become overwhelmed by the perceived demands of others are characteristic stresses of the multicultural condition described as "dilletantism," by Adler or "deracine cosmopolitan" by Stonequist. It is the tendency to move from experience to experience without commitment, and is marked by superficiality and avoidance of problems. Only one 
interviewee demonstrated having these difficulties. Her case was previously mentioned in Multicultural Transitions and Identifications as it is a condition reflective of developing adaptational skills to the degree that the inner core of the self is lost. This characteristic was not salient in the data, however it is a difficulty that may occur in others, and therefore should not be ignored.

\section{Multicultural Mediation Tendencies}

The exploration of the participants' cultural mediation tendencies was centered around three major areas. Interviewees were asked to comment upon: their tendencies toward taking intermediary roles and mediating problem situations; the ways their cross-cultural experiences have affected their career choices, and directions; and the special skills they felt they'd developed as a result of multicultural interactions. Their responses were analyzed with reference to the particular attitudes, awarenesses, behaviors and communication styles Stonequist, Adler, Bochner, and Taft described as indicative of "mediating" or "inter mediary" personalities.

15) All but one of the respondents were interested and involved in mediating problem situations. The career choices and directions selected by participants substantiated two themes from the literature: 16) engagement in future oriented, creative work, and 17) a desire to contribute to international understanding. Three themes emerged in the data concerning special skills. These were: 18) adaptability; 19) language learning; and 20) the ability to recognize and communicate within different cultural orientations. (Termed empathy, understanding different points of view, communicating, etc. by the interviewees. Termed "changing cultural 
orientations," "shifting frame of reference," and "empathy" by the selected authors).

15) Taking an intermediary role and mediating problem situations

Seven of the interviewed persons indicated that they involved themselves in mediation roles when problem situations and miscommunications occurred. The statements quoted from SP, LH, amd BW are reflective of the majority of the study group. JS was the only respondent that did not mention involving herself as an inter mediary or mediator.

SP: I want to clear it up. I want to say, "Look, listen to each other for a minute, just really listen." I would try to convince them that they are not understanding each other, there's a communication problem.

LH: I take a mediating position in general, just to try and make sure these people are actually talking, not at each other, but talking to each other and listening to each other.... I don't know, I think people need to educate themselves about whatever culture they're dealing with alot more than they have, and not make as many assumptions about their own cultures being the one and only. It's fine to have beliefs that what you believe is right. I think that's fine, you can do that, but you should be aware that there are other worldviews that are, that can be, equally valid as yours and should be taken into consideration. And one shouldn't make assumptions that just because you believe something that everyone else does.

BW: I immediately begin to interpret for them. Break up, break right in the middle of it, whether it's my job to do that or not, and explain to one person what the other person is saying, ask them to be quiet, take that person, what that person was saying and explain it to the other person, explain to them.

M]: I try to get them to understand the other culture in a basic way. try to overcome that "we/they". . . scenario, and try to develop an appreciation for the wider, for each other's culture. To overcome those kinds of possible racial or ethnic prejudices, and gain an appreciation that there just are differences. 
JS: I might try to mitigate it but more of ten than not I leave. I have nothing to say when people are that unaware. What's the point?

Career choices, and directions include: 16) Future oriented, creative work (Bochner and Taft), and 17) a desire to contribute to international understanding (Stonequist, Adler, Bochner, Taft).

When asked about the ways cross-cultural experiences affected their career choices and directions, all eight respondents spoke of being directed toward internationally involved, creative endeavors. Each of them discussed their commitments to making the world a better place. This orientation is in agreement with the theoretical position that multiculturals have a desire to contribute to international understanding as their general purpose in life. The following passages are indicative of these sentiments:

BW: In all the jobs, all the professions I've been involved in, I've always seemed to be in a helping profession. . . My goal is to get employment where I would be allowed to travel. That's something I haven't achieved yet, but that is my ultimate goal, and that's definitely because of having traveled. I think that, those of us who grew up internationally tend to, whether it's in careers or in personal life, tend to get involved in, with people, in helping professions. It seems to me that, we have a -- like, it's up to us to solve whatever problems come along. It's almost like a need. And, I'm not sure why that is, but that feels right to me.

SP: I've decided that I want to probably work abroad in maybe agriculture or agronomy, or plant research -- and I think I want to help other people. Help other people meaning USAID, or World Health, or CARE, something like that, in that kind of organization. I think I want to work for that but I'm not sure. I know I want to travel, and I know I want to live abroad and be in some area that I could really help people, like agriculture.

JS: I'm involved with mass communications and humanity. An interest in the world at large. An interest in reaching a large amount of people and communicating to them.

M]: I'm real involved in problem situations between the environmentalists and the developers. They're culturally distinct you know. 
Special skills interview subjects attributed to multicultural upbringings.

The most frequently mentioned skills the interview participants felt they had developed as a result of their multicultural interactions were 16) adaptability; 17) language learning; and 18) the ability to recognize and communicate within different cultural orientations. (Termed empathy, understanding different points of view, communicating, etc. by interviewees, and termed changing cultural orientations, shifting frame of reference, and empathy by selected authors).

All eight respondents mentioned developing proficiency in language learning and adaptability, as well as in understanding, appreciating, and communicating within different cultural orientations. Each of these attributes was also discussed in the selected literature. The following examples are illustrative of the participants' responses:

BW: I think I'm adaptable, I think that, I'm a good listener, I think I'm a much better listener than if I hadn't lived overseas. I think I have a real talent for picking up languages, having lived overseas. . . I think it's just basically being adaptable and all that the word adaptable entails, being able to move around, to $g 0$ into these situations, clear sight, -- I view it as clear sight. ... oh, and being able to see all the different angles, being able to empathize with, other people and their situations.

SP: Probably adapting to certain cultures. I think that's a habit you pick up, or something you learn, dealing with people in a diplomatic way. Yeah, patience, tolerance, adaptability. Broadening my perspective.

PL: I work in mental health and, there's a French woman, who's only other language is Spanish, and, when she would come into the mental health unit, if her husband wasn't there, the only other person she could speak with would be me. Alot of times where 1 do my interpreting is in the emergency room. -- I don't want to lose it. I think it's a real asset to be able to speak another language. 
M]: Language is one, but more than that, an ability to deal with people of widely differing cultures, widely differing opinions, even within the United States. I feel I can come across to people whether they're a cowboy that doesn't get to town but once a month; or a downtown city planner whose phone is ringing off the hook and is dealing with zoning problems; or a totally anti-social hipped out person that's out being a survivalist; an illegal alien, Merican, Guatemalan, whatever. I feel I can relate to those people real well, and communicate with a wide range. I feel pretty good about being able to communicate with virtually anybody. And, that stems from my background.

PE: Because of my my experience, I believe $I$ can appreciate different cultural perspectives, and even philosophical perspectives enough to be able to act as a liason or intermediary.

Aside from directly reporting their skills in understanding different cultural orientations and frames of reference, sir interviewees also demonstrated a recognition of the need and the ability to change cultural frames of reference in certain situations. This is eremplified in the following quotes from $\mathrm{PE}$ and $\mathrm{SP}$.

PE: When the Shah of Iran came, there were some riots and demonstrations in the street, and 1 rode my bicycle to school this one day and actually I got stopped by the crowd and thrown to the ground. My bicycle was broken, I was spit on, they called me dirty American, etc. etc., and my reaction was really -- not even to say that I wasn't American, because I found myself sort of protecting the American image against the Pakistanis. I felt affronted by this , and didn't say "No, l'm Canadian." sort of thing. I acted like I was American and responded to the principle. When I went to school and told the story to the class, and the response was "Well, they're dumb." Then I found myself standing up in front of the class saying "Don't be so stupid, don't be so narrow minded, you've got to understand why there's frustrations." And I think that was one of the most poignant times to me when I realized that I guess because I'd been there longer, had the language, was familiar with the culture, that $I$ was beginning to appreciate some of the things that some other people didn't appreciate.

SP: In decision making, I mean thinking about things that are happening in a country that perhaps you've been in, you try to think of how those people would think about that decision. I don't feel like I would really 
know, because I don't think I know the culture as well. But, I try to step back and look at things from their point of view, given their circumstances, instead of just off the top of my head making a decision.

Seven out of the eight study group members show the qualities attributed to intercultural mediators in the surveyed literature. All seven of them tend to take intermediary roles when they recognize problem situations centered around communication difficulties. They seek to establish and balance communication, attempt to facilitate action and understanding, and can be described as translators and synthesizers who may serve as bridges between cultures as is surmised by each of the surveyed authors. All of the interviewees are engaged in future oriented, creative work, and expressed the desire to contribute to international understanding. They see themselves as adaptable and proficient in language learning. They are interested in and able to recognize different cultural orientations and communicate with people from varied cultures and subcultures.

The individual who did not describe herself as a mediator is engaged in future oriented, creative work, and has the desire to effect global change. She is adaptable and proficient in language learning and is interested in different cultural and sub-cultural orientations.

Although the ability to perceive and anticipate potential frustrations between diverse cultural groups (Bochner, Taft) may be inferred by the attitudes and knowledge of many of the study participants, this skill was not claimed by the informants and therefore did not arise as a salient characteristic of the group. This theme was not confirmed by this study. 
The unique capacity for nearness and sympathetic understanding was attributed to multiculturals by Stonequist. He claimed that they are often perceived as confidants, and have a particular capacity for what he termed "sympathetic objectivity." Whereas all eight interviewees said they served as confidants, they did not claim to have superior skills in this area. The self-report nature of the interview questions, and the modesty of the individuals may not allow full coverage of a theme such as this.

\section{Summary}

The results of the data analysis lead the researcher to suppose that exposure to multiple cultural environments during the formative years has a profound effect on the psychosocial development of individuals having this experience. All eight interview participants developed certain attitudes and behavior patterns in common. Thus, it can be hypothesized, that adults whose childhood years were spent in multiple cultural environments develop certain recognizable manifestations of their multicultural socialization experiences.

Thirteen themes surfaced universally among the interview subjects. Five themes surfaced among seven out of the eight participants. These themes are labeled in terms consistent with the literary descriptions provided by the surveyed authors and are summarized below. Sir literary themes are not supported by the interview data. A discussion of these literary themes and possible rationale's for the non-supportive outcome of the interview data follows the summary of the themes that do characterize the study group. 
The following list of multicultural attributes emerged as characteristic of the entire multiculturally socialized study group:

\section{Multicultural Enculturation:}

1) The foundations of cultural identity are shaken, whereby individuals are exposed to and interact in multiple cultures to the ertent that they lose their sense of identification with one cultural reality (Adler).

2) Crisis of discovering cultural differences which become a source of inner conflict due to identification with each group, or to an inability to fully identify with any cultural group wholeheartedly (Stonequist, Bochner, Taft). Multicultural Transitions and ldentifications;

*3) Development of an international reference group (Bochner and Taft) or a sense of belonging with other individuals having international experience, regardless of nationality.

4) Frequent personal transitions (Stonequist, Adler, Bochner, Taft). were identified as part of a fluid identity pattern predicated on a need for change.

*5) Contextual adaptability (Stonequist, Adler, Bochner, Taft) is fleribility and adaptiveness to new situations and contexts. Multicultural Perspectives:

*6) Cultural relativism, or the recognition that each culture is equally valid in that it has its own internal coherence and integrity (Adler, Bochner, Taft). 7) Non-judgementainess, or not judging one situation in terms of another, but suspending judgement until the contert enveloping the situation is understood (Stonequist, Adler, Bochner, Taft). 


\section{Multicultural Stresses:}

8) Lack of belonging , or feeling like a stranger that is outside most groups, and does not belong completely to any culture (Stonequist, Adler, Bochner, Taft).

9) Identity issues arising from socialization in multiple cultural environments (Stonequist, Adler, Bochner, Taft).

10) Detachment, aloofness and indifference stemming from this inability to feel part of a group (Stonequist, Adler, Bochner, Taft).

\section{Multicultural Mediation Tendencies:}

*11) Engagement in future oriented, creative work (Bochner and Taft).

*12) A desire to contribute to international understanding (Stonequist, Adler, Bochner, Taft).

*13) Language learning (Stonequist, Adler, Bochner, Taft)

The following attitudes and behaviors were expressed by seven of the eight multiculturally socialized informants. While not universally applicable to each person's experience, they are noteworthy as possible outcomes of a heterocultural upbringing.

Multicultural Enculturation:

1) Maintenance of inner coherence through varied situations and contexts (Stonequist, Adler, Bochner, Taft).

\section{Multicultural Perspectives:}

2) Worldmindedness, or a sense of internationalism whereby loyalties are to humankind rather than to separate nations (Stonequist, Adler, Bochner, Taft).

3) Commitment to the fundamental unity of all peoples. 
Multicultural Mediation Tendencies:

4) Taking an intermediary role and mediating problem situations (Stonequist, Adler, Bochner, Taft)

5) The ability to recognize and communicate within different cultural orientations (Stonequist, Adler, Bochner, Taft).

The following themes were noted by fewer than seven of the eight interviewees and are therefore "suspect" by the criteria of this study.

\section{Multicultural Enculturation:}

Partial assimilation of more than two cultures, whereby individuals incorporate attitudes, behaviors, and communication patterns characteristic of each culture was claimed by only five interview participants. This is somewhat discrepant with Stonequist, Bochner, and Taft, who claim that multicultural identity formation must include some assimilation of more than two cultures. Adler claims that it is the internalization of a psychoculturally diverse sense of awareness which may or may not include cultural assimilation that creates the multicultural identity pattern. Adler's view is born out by the data.

An explanation of this discrepancy may be that the selected authors and the study participants have different definitions of assimilation. Or, the discrepancy may be in the interview subjects' awareness of assimilation as several of the participants, who felt they could not say they had become a part of the societies in which they lived, had perspectives and attitudes reflecting some cultural assimilation. In other cases, the actual incorporation of values, beliefs, and communication modes from each culture into one's unconcious perceptual scheme are not apparent. 
Multicultural Perspectives:

The paradoxical commitment to both the similarities that unite all peoples across cultures, as well as to the recognition and respect of cultural diversity was described by Adler as characteristic of the multicultural individual. The total commitment each of the interviewees repeatedly expressed to cultural relativism is indicative of this position. However, the evidence in support of this paradorical commitment is not clear enough in the interview data to say that this theme unanimously characterizes the study group. Further exploration of this issue is in order, for this theme is not confirmed by this study.

\section{Multicultural Stresses:}

Stonequist theorizes that one of the most severe difficulties experienced by the marginal individual is psychological identification without acceptance from a particular group. None of the interview subjects attributed their feelings of alienation to being excluded from groups with which they identified. They feel that the difficulties they experienced concerning a lack of belonging stem from their own inabilities to identify with them; thus, they exclude themselves from group membership. This theoretical position is not substantiated by this research.

The multicultural condition Adler describes as "dilletantism" and Stonequist describes as "deracine cosmopolitan" is characterized by excessive internal flexibility and vulnerability to stimuli, as well as a tendency to become overwhelmed by the perceived demands of others. It is the tendency to move from experience to experience without commitment. It is a condition reflective of developing adaptational skills to the degree that the inner core of the self is lost, and is marked by superficiality and avoidance of 
problems. This characteristic is not salient in the data, as only one interviewee demonstrated having these difficulties.

\section{Multicultural Mediation Tendencies:}

Bochner and Taft claim that mediating persons have the ability to perceive and anticipate potential frustrations between diverse cultural groups. Although the attitudes, awarenesses, and cultural knowledge of many of the study participants are indicative of having this ability, this skill was not claimed by any of the informants. It therefore does not arise as a salient characteristic of the group, and is not confirmed by this study.

Stonequist claims that multiculturals are often perceived as confidants, and have a particular capacity for nearness and sympathetic understanding. He terms this characteristic "sympathetic objectivity." All eight interviewees said they served as confidants, however they did not claim to have superior skills in this area. The self-report nature of the interview questions, and the modesty of the individuals may not have permitted full coverage of a theme such as this. Therefore, the quality of having a unique capacity for "sympathetic objectivity" is not confirmed by this research. 


\section{CHAPTER V}

\section{LIMITATIONS, APPLICATIONS,}

AND

SUGGESTIONS FOR FURTHER RESEARCH

\section{Limitations}

The final phase of qualitative analysis involves the researcher's attempt to understand the data in the contert in which it is collected (Taylor and Bogdan, 1984 ). This is what Deutscher (1973) and Mills (1940) call discounting the data. It is a manner of assessing credibility by taking how the data is collected and interpreted into consideration. There are several considerations outlined by Taylor and Bogdan that are pertinent to this study: 1) Solicited or unsolicited data. 2) Researcher's influence on the interview participants. 3) Sources. 4) Researcher's assumptions and presuppositions.

1) Solicited or unsolicited data. The research data is solicited through questioning based on the interview schedule of questions, as well as conversational follow up probes and comments. There is also spontaneous talking on the part of participants. The unsolicited data is not noticeably different from the responses to the questions as the volunteered information is usually sparked by memories and took the form of tangential or anecdotal validation of core issues. 
2) Researcher's influence on the interview participants. The researcher's involvements with the interviewees is in keeping with the humanistic nature of qualitative research. She got to know the interview subjects personally and learned about their inner life strugsles, successes, and failures (Shaw,1931).

3) Sources. Taylor and Bogdan (1984) state that generalizing about a group of people based upon the responses of a few is a danger in naturalistic inquiry. The researcher experienced this type of bias in an initial stage of coding the interview data. A few informants were so emphatic and articulate that several themes appeared overwhelmingly representative of the study group. Further analysis revealed that this was not true. Often, one person expressed the same concepts several times throughout the interview sessions.

4) Researcher's assumptions and presuppositions. Qualitative researchers recognize that it is impossible to totally avoid one's own biases. Because data are never self-explanatory, all researchers use their own theoretical assumptions and knowledge to interpret their data. The best check on one's biases is critical self-reflection (Taylor and Bogdan,1984).

This researcher identified herself to a large degree with the interview participants as she herself was enculturated in multiple international environments. One of her motivations in researching this topic is to explore the congruency between her own positive and negative qualities and those of a wide range of individuals having little more than international involvements during childhood in common. The intent of this investigation is to discover specific attitudes and behaviors that could be attributed to experiences in multiple cultural milieux. 
5) This study is also limited in that it is a preliminary investigation and does not employ cross validity measures. This could be accomplished by: a) using the interviews with a comparison or control group to measure the occurrence of similar attributes in monocultural persons; b) employing a cross validation rater to see if data would be interpreted the same way by another individual; or c) using a cross validation sample consisting of another group of multiculturally socialized individuals to see if their responses correlate with those found in this study.

\section{Practical Applications}

The findings in this exploratory study have illucidated some of the possible outcomes of exposure to multiple cultural environments during childhood. The themes which surfaced through the data analysis may serve as guides in the recognition of the characteristics of multiculturally socialized individuals. They may also be useful in suggesting certain strategies to help heteroculturals cope with the stresses and tensions arising from their experiences.

The entire research group indicated that their exposure to and interaction in multiple cultures increased their awareness of multiple realities to the extent that they lost, or never developed, a sense of identification with a single cultural reality. Adler describes this phenomenon as having the foundation of one's cultural identity shaken to the degree that one develops a psychoculturally-diverse sense of awareness. This condition is construed as unsettling but not necessarily negative by the majority of the study group. However, it contributes to the development of identity issues and vulnerabilities as well as a lack of inclusion. The most 
distressful symptom is feeling like a stranger that is outside most groups, and does not belong completely to any culture. Often, detachment, aloofness and indifference stem from this inability to feel a sense of belonging.

Certain needs surfaced commonly among the study group members. It appears that the stimulation and excitement of moving and experiencing total cultural and environmental changes throughout the developmental years has been influential in developing a group of individuals that engage in frequent personal transitions and feel a need for the stimulation brought about by change. All of the informants want to keep travel as a part of their lives and feel the need to communicate cross-culturally. They feel the greatest sense of inclusion with other individuals that also have international experience, regardless of nationality.

The information in this paper has the potential for assisting counselors and other professionals who work with multicultural individuals. It can be used as a tool to help them recognize, anticipate or analyze the occurrence of specific assets, needs and difficulties that may be related to the experience of having cultural adjustment as a way of life during one's formative years. In order to cope successfully with the stresses arising from heteroculturality, it may be helpful to recognize the sources of one's differences from other cultural members, whether these differences are perceived as strengths or as weaknesses. This can be approached by applying the scheme that emerged from the qualitative analysis of the literature. This scheme organizes multicultural attributes into five major categories concerning: 1) Multicultural Enculturation; 2) Multicultural Transitions and Identifications; 3) Multicultural Perspectives, 4) Multicultural Stresses; and 5) Multicultural Mediation Tendencies. The systematic application of this scheme as a frame of reference through which one attempts to understand multiculturally 
socialized individuals, can help predict, organize, and clarify some of the particular attitudes, behaviors, and communication patterns characteristic of this group.

Situations in which specific applications of this information would be useful include: cross-cultural training and re-entry programs; refugee resettlement programs; schools and colleges; loster care programs; social services and health care; as well as business organizations that employ or work with people having multiple cultural affiliations.

Multicultural individuals have a need to contribute to the world, and to be involved in what they consider to be meaningful work. Society would also benefit if their skills could be utilized more effectively. Multicultural people may be found to be exceptionally adept at certain positions because of the characteristics which typify them. The research data gathered from both the literature and the interviews indicate that they are particularly suited for positions as mediators. They are also well suited for involvement in situations that require adaptability, cultural relativism, and the tendency not to evaluate one situation in terms of another, but to suspend judgement until the context enveloping the situation is understood.

Some conterts in which these skills may be useful are: international and inter-ethnic communication, education, planning, counseling, and government relations.

Multiple cultural involvements develop assets and skills that are relevant in today's highly mobile world. Among them are adaptability, and a positive attitude toward change. All of the interview subjects are now involved in, or are aspiring toward socially conscious, creative work at the completion of their current studies. They are committed to contributing to international understanding. They accommodate easily to new situations, 
conterts, and expectations, and see themselves as proficient in language learning.

More and more people are finding themselves involved in crosscultural interface situations both internationally and domestically, within the United States. As this cross-cultural contact increases, so does the need for improved intercultural communication strategies. It is important to develop strategies that help these individuals use their talents constructively, rather than lose themselves in their inabilities to cope with the often debilitating stresses inherent in their "between-culture" positions.

\section{Suggestions for Further Research.}

Even though the variables of racial, ethnic, and/or economic group dominance, and the motivation for cross-cultural involvement (choice for sojourners, versus necessity for refugees) are significant, this researcher believes that there are notable commonalities among these groups of multiculturals that the information presented in this exploratory study may address. More specific research needs to be done in order to determine which strategies are the most effective for whom.

Before the development of such strategies occurs, the validation of this study by the use of a more rigorous research design may be in order. This may be accomplished in several ways: 1) by employing cross validation raters to see if data would be interpreted the same way by other individuals; 2 ) by using cross validation samples consisting of other groups of multiculturally socialized individuals to see if their responses correlate with those found in this study; 3) by interviewing a comparison or control group to measure the occurrence of these attributes in monoculturally 
socialized individuals; or 4) by creating a reliable instrument based on the multicultural themes that emerged as salient in this study capable of measuring the occurrence of these attributes, and testing other groups of multiculturally socialized individuals as well as control groups to measure monocultural persons.

A great deal of literature has described the "tragic" or "transcendent," "adjusted" or "maladjusted" positions of heterocultural individuals, yet, one large question has not been addressed. What separates the two? Are there specific identifiable factors that determine whether an individual will rise and become a dynamic synthesizer and cultural mediator or fall and become lost, detached, alienated, and ineffectual?

Identification of the variables leading some heterocultural people to develop cultural awareness as an ability that can be used to their advantage is desirable.

Identity crises have been cited as being among the most crucial problems for dual-culture learners of our time (Sommers, 1964). Can strategies used to help multiculturally socialized individuals develop a positive construal of their position be applied to dual-culture learners as well? 


\section{BIBLIOGRAPHY}

Adler, P.S. Beyond cultural identity: Reflections upon cultural and multicultural man. In R. Brislin (Ed.), Topics in Culture Learning August 1974, 2, 23-40.

Adler, P.S. The transitional experience: An alternative view of culture shock. Journal of Humanistic Psychology, Fall 1975, 15 , 13-23.

Asante, M.K., Newmark, E., and Blake, C.A. (Eds.). Handbook of intercultural communication. Beverly Hills: Sage Publication, 1979.

Barna, L. Stumbling blocks in intercultural communication. In L.A. Samovar and R.E. Porter (Eds.), Intercultural communication: $A$ reader.

Belmont, CA: Wadsworth Publishing Co., Inc., 1982.

Barnlund, D. Interpersonal communication: Survey and studies. Boston: Houghton Mifflin, 1968.

Barnlund, D. Public and private self in Japan and the United States. Tokyo: Simul Press, Inc., 1975.

Benedict, R. Patterns of culture. New York: Mentor, 1948.

Bennett, M.J. Towards ethno-relativism: A developmental model for intercultural sensitivity. Paper delivered at the Annual Conference of the Council on International Educational Exchange, Minneapolis, Minn., 1984.

Berger, P., \& Luckman, T. (1967). The social construction of reality. Garden City, N.Y. : Doubleday.

Berry, J.W. Marginality, stress and ethnic identification in an aboriginal community. Journal of Cross Cultural Psychology 1970, 1 232-252.

Bochner, $S$. The mediating man and cultural diversity. Topics in Culture Learning 1973, 1, 23-37. 
Bochner, S. The mediating man: Cultural interchange and transnational education. Honolulu: Culture Learning Institute, 1973.

Bochner, $S$. (Ed.) The mediating person: Bridges between cultures. Cambridge, Mass. : Schenkman, 1981.

Brislin, R. Cross-cultural encounters. New York: Pergamon Press, 1981.

Brislin, R., Lonner, W., \& Thorndike, R. Cross cultural research methods. New York: John Wiley \& Sons, 1973.

Brody, E. B. Color and identity conflict in young boys. Psychiatry. 1963, 26, 188-201.

Chance, N.A. Acculturation, self-identification, and personality adjustment. American Anthropologist, 1965, 67, 382-393.

Clark, K.B., \& Clark, M.K. Racial identification and preference in Negro children. In M. Newcomb, \& E.L. Bartley (Eds.), Readings in social psycholosy. New York: Holt, Rienhart \& Winston, 1947.

Clark, M., Kauf man, S., Pierce, R.C. Explorations of acculturation: Toward a model of ethnic identity. Human Organization, 1976, 35, 231-238.

Condon, J.C., \& Yousef, F.S. An introduction to intercultural communication. Indianapolis: Bobb-Merrill Educational Publishing, 1980.

Dabrowski, K. Positive disintegration. Boston: Little, Brown \& Co., 1964.

Derbyshire, R.L. \& Brody, E.B. Marginality, identity and behavior in the Negro: A functional analysis. International Journal of Social Psychiatry, 1964, 10, 7-13.

Deutscher, I. What we say/what we do: Sentiments and acts. Glenview, III. : Scott, Foresman, 1973.

Downie, R.D. Re-entry experiences and identity for mation of third culture experienced dependent American youth: An exploratory study. Unpublished Ph.D. dissertation, Michigan State University, 1976.

Eysenck, S.B.G. One approach to cross-cultural studies of personality. Australian Journal of Psychology 1983, 35, 381-391. 
Fanfan, L., Joven, V.M., Pathammavong, K., Khoa, L.X., Lourie, N., Pimenta, C., Schrader, $K$., and VanDeusen, J. Social adaptation of refugees: A guide for service providers, 1983, Washington, D.C. : Center for Applied Linguistics.

Fitzgerald, J.K. Education and identity: A reconsideration of some models of identity. New Zealand Council of Educational Studies, 1979.

Friere, P. Cultural action for freedom. Cambridge: Harvard Educational Review Press, 1970.

Githens, M., \& Prestage, J. Women state legislators: Styles and priorities. The Policy Studies Journal, Winter 1978, Z(2), 264-270.

Glaser, B.G., \& Strauss, A.L. The discovery of grounded theory: Strategies for qualitative research. New York: Aldine Publishing Co., 1967.

Gleason, T.P. Social adjustment patterns and manifestations of worldmindedness of overseas-experienced American youth. Unpublished Ph.D. dissertation, Michigan State University, 1970.

Goldberg, M.W. A qualification of the marginal man theory. American Sociological Review, 1941, 6, 52-58.

Guthrie, G.M. A behavioral analysis of culture learning. In R.W. Brislin, S. Bochner, \& W.J. Lonner (Eds.), Cross-cultural perspectives on learning. New York: Wiley, 1975.

Hall, E.T. The silent language. New York: Doubleday, 1959.

Hall, E.T. Beyond culture. New York: Doubleday, 1976.

Herskovits, J.J. Man and his works. New York: Knopf, 1948.

Herskovits, J.J. Cultural relativism: Perspectives in cultural pluralism. New York: Random House, 1972.

Hoopes, D.S. Intercultural communication concepts and the psychology of intercultural experience. In M. Pusch (Ed.), Multi-cultural education. Chicago, IL: Intercultural Network, Inc., 1981. 
Hoopes, D.S., \& Pusch, M.D. Definition of terms. In M. Pusch (Ed.), Multicultural education. Chicago, IL: Intercultural Network, Inc., 1981.

Kelly, G. The psychology of personal constructs. New York: Norton, 1953.

Kluckhohn, F.R., \& Strodtbeck, F.L. Variations in value orientations. New York: Harper and Row, Publishers, 1961.

Jones, E.E., \& Nisbett, R.E. The actor and the observer: Divergent perceptions of the causes of behavior. In E. E. Jones, et al. (Eds.), Perceiving the causes of behavior. Morristown, NJ: General Learning Press, 1971.

Lazerson, M.L. The school as melting pot: Pluralism and Americanization vie for dominance. Civil Rights Digest, 1978, 9 19-27.

Lufzker, D. Internationalism as a predictor of cooperative behavior. Journal of Conflict Resolution, 1960, 4(4), 426-430.

Lum, J. Marginality and multiculturalism: Another look at bilingual/bicultural education. Culture Learning Institute Report, June 1977, Vol. 5, No.1.

Mead, G.H. Mind, self and society. Chicago: University of Chicago Press, 1934.

Mills, C.W. Situated actions and vocabularies of motive. American Sociological Review, 1940, 2 904-913.

Nehru, J. An autobiography. London: Bodley Head, 1936.

Paranjpe, A.G. In search of identity. New York: Halstead Press, 1975.

Park, R.E. Human migration and the marginal man. American lournal of Sociology 1928, 33, 881-93.

Pedersen, P., Lonner, W., \& Draguns, J. (Eds.). Counseling across cultures. Honolulu: The University of Hawaii Press, 1976.

Porter, R.E., \& Samovar, L.A. Communicating interculturally. In L. Samovar and R. Porter (Eds.), Intercultural communication: A reader. Belmont, CA: Wadsworth, 1982. 
Redfield, R. The folk culture of Yucatan. Chicago: Univer sity of Chicago Press, 1941.

Redfield, R. A village that chose progress. Chicago: University of Chicago Press, 1950.

Rist, $R$. On the relations among education research paradigms: From disdain to detente. Anthropology and Education. 1977, 1 (2), 42-50.

Roe, P. G. Marginal men: Male artists among the Shipibo Indians of Peru. Anthropologica, 1979, 21 (2), 189-221.

Samovar, L., \& Porter, R. Intercultural communication: A reader. Belmont, CA: Wadsworth Publishing Co., 1982.

Sampson, D.L., \& Smith, H.P. A scale to measure world-minded attitudes. Journal of Social Psycholosy 1957, 45, 99-106.

Sarbaugh, L.F. Intercultural communication. New Jersey: Hayden Book Co., 1979.

Secord, P.F., \& Backman, C.W. Social psychology. New York: McGraw-Hill, 1964.

Selltiz, C., Jahoda, M., Deutsch, M., \& Cook, S.W. Research methods in social relations. New York: Henry Holt and Co., Inc., 1960.

Shattuck, G.M. Between two cultures: A study of the social adaptation of foreign students to an American academic community. Ithaca, NY: Department of Rural Sociology, Cornell University, 1965.

Shaw, C. The natural history of a delinquent career. Chicago: University of Chicago Press, 1931.

Sherif, M. The concept of reference groups in human relations. In M. Sherif and M.O. Wilson (Eds.), Group relations at the cross-roads. New York: Harper and Brothers, 1953.

Sherif, M. Groups in harmony and tension. New York: Octagon Books, Inc., 1966.

Shibutani, T. Reference groups as perspectives. American Journal of Sociology, 1955, 40(5), 562-659. 
Shibutani, T. Society and Personality. Englewood, NJ: Prentice Hall, Inc., 1961.

Singer, M.R. Culture: A perceptual approach. Readings in Intercultural Communication, 1976, 1, 6-20.

Sommers, V.S. The impact of dual-cultural membership on identity. Psychiatry 1964, 27(4), 332-344.

Stewart, E.C. American cultural patterns. Chicago, IL: Intercultural Press, Inc., 1972.

Stonequist, E.V. The marginal man. New York: Scribner, 1961.

Stonequist, E.V. The problem of the marginal man. American lournal of Sociology, 1935, 1-12.

Sue, D.W. Counseling the culturally different: A conceptual analysis. Personnel and Guidance Journal, 1977, 3, 422-425.

Sue, D.W. Counseling the culturally different. New York: John Wiley \& Sons, 1981 .

Sue, S., \& Wagner, N. Asian Americans: Psychological Perspectives. Palo Alto, CA: Science and Behavior books, Inc., 1973.

Swain, M. Bilingualism as a first language. Unpublished doctoral dissertation, University of California at Irvine, 1972.

Taft, R. The role and personality of the mediator. In S. Bochner (Ed.), The mediating person: Bridges between cultures, Cambridge, Mass. : Schenkman, 1981.

Taylor, S.J., \& Bogdan, R. Introduction to qualitative research methods: The search for meanings. New York: John Wiley and Sons, Inc., 1984.

Throssell, R.P. Towards a multi-cultural society: The role of government departments and officials in developing cross-cultural relations in Australia. In S. Bochner (Ed.), The mediating person: Bridges between cultures. Cambridge, Mass. : Schenkman, 1981. 
Triandis, H.C. The analysis of subjective culture. New York:

Wiley/Interscience, 1972.

Tucker, R.K., Weaver, R.L., \& Berryman-Fink, C. Research in speech communication. NJ: Prentice-Hall, Inc., 1981.

Useem, R.H. Education of third culture children: An annotated bibliography. Studies of third cultures: A continuing series, Michigan State University: Institute for International Studies in Education, 1976.

Useem, J., \& Useem, R.H. The interfaces of a binational third culture: A study of the American community in India. Journal of Social Issues, 1967, 23(1), 130-143.

Useem, J., Useem, R.H., \& Donoghue, J. Men in the middle of the third culture: The roles of American and non-Western people in cross cultural administration. Human Organization, 1963, 22, 169-179.

Waltz, C.F., Strickland, 0.L., \& Lentz, E.R. Measurement in nursing research. Philadelphia: F.A. Davis Co., 1983.

Werkman, S., Farley, K., Butler, C., \& Quayhagen, M. The psychological effects of moving and living overseas. Journal of the American Academy of Child Psychiatry 1982, 20, 645-657.

Whorf, B.L. Language, thought and reality. Cambridge, Mass. : Wiley, 1956.

Willie, C.V. Marginality and social change. Transaction/Society July/August 1975, 10-13. 
APPENDIX A

PRELIMINARY THEMATIC ANALYSIS

\section{Multicultural Enculturation;}

Demographic Screening instrument and Questions 1-8

Primary Familiogenic Multiculturalism Type 1 and Type II Secondary Idiogenic Multiculturalism

Psychoculturally diverse sense of awareness

Inability to identify with one cultural reality

Foundations of cultural identity shaken

Partial Assimilation of Cultures

Crisis of discovering cultural differences

Inner conflict due to identification with each cultural group

\section{Multicultural Transitions and Identifications;}

(Questions 9-14,16-21, and).

International reference group

Frequent personal transitions

Contertually adaptive

Maintain stability and inner coherence through change

Culture shock part of identity formation

Culture shock minimal due to experience with cultural change

Need for growth and change

Cyclic pattern of personality development

Repeated disintegration and reintegration of the psyche

Higher levels of integration each time, implicit growth

Evolutionary beings

\section{Multicultural Perspectives; \\ (Questions 11,15 and 22-32)}

Globalist, universalist perspective

Worldmindedness

Commitment to both similarities and differences

Cultural relativism

Non-judgementalness 


\section{Multicultural Stresses;}

(Questions 9,10,11,13,14,18,19,21,28,29,33-40)

Lack of belonging

Erists on margins of cultures and groups, partly in, partly out

Pain is in attempt to identify and belong

Unfulfilled belonging needs result in loss of objectivity

Psychological identification without acceptance

Identity confusion

Vulnerability and stress

Superficiality

Avoidance of real human problems

Internal fleribility

Overwhelmed by conflicting interests and demands of others

Excessively vulnerable to stimuli

Detachment, aloofness and indifference

"Dilletantism"/"deracine cosmopolitan"

\section{Multicultural Mediation Tendencies}

(Questions 15,22,28,29,30, 41-45)

Ability to shift frame of reference

Ability to serve as bridge between cultures

Ability to interact in unfamiliar cultures in a relaxed manner

Seek to establish and balance communication

Facilitate action, and understanding

Interpret expressions intentions and perceptions of each group to the other

Take inter mediary roles

Future oriented creative work

Develop language skills

Have knowledge of cultural roles and expectations

Ability to perceive and anticipate potential frustrations between diverse cultural groups

General purpose to contribute to international understanding

Are translators and synthesizers

Are free from local prejudices and values

Unique capacity for nearness and sympathetic understanding

Relationship of confidant

Sympathetic objectivity 


\section{APPENDIX B \\ DEMOGRAPHIC SCREENING INSTRUMENT}

Subject

Date of birth

Mother's ethnicity

Father's ethnicity

Citizenshio/residency

Contact with host nationals

Familiarity $w /$ languages of host countries

Familiarity w/social norms of host countries

City, Country Composition of living environment

Years

(ie. compound, boarding school, host

from - to national or expatriate neighborhood etc.) 


\title{
APPENDIX C
}

\section{PRIMARY ENCULTURATION OF INTERVIEW PARTICIPANTS}

\author{
$\begin{array}{llll}\text { SUBJECT } & \text { AGE } & \text { PLACE }\end{array}$
}

JS

ANGLO-AMERICAN/

RUSSIAN-JEWISH

$0-2$

Tegucigalpa, Honduras

urban/suburban

$2-5$

$5-7$

Caracas, Venezuela

7-12 Santiago, Chile

12-17 Panama City, Panama

17-18.5 San Salvador, El Salvador/

New Orleans, LA /

San Francisco, CA USA

18.5-19 Tempe, AZ USA /

Mazatlan, Merico

19-25 Hood River, OR

rural

Ashland, OR

Grande Ronde, $\mathrm{OR}$

urban/suburban

Canada, CA

travel

25-26 Honolulu, Hawaii

Maui, Hawaii

27-27.5 Hood River, OR USA

rural

$27.5-28$

French West Indies,

Isle de Sante, New York City,

travel

London, India, Nepal,

Paris, Mayorca, Wa. D.C.

28-31 Eugene, $O R$

31- Olympia, WA

urban/suburban college

JP

FRENCH/

RUSSIAN-JEW ISH

0-6

Santiago, Chile

urban/suburban

6-9 London, England

school dormitory

9-12

Vienna,Austria

urban/suburban 

12-16 Santiago, Chile
16-18 Buenos Aires, Argentina
18-25 Portland, OR, USA college/urban,suburban
Europe,
South America
25-29 Vietnam
Thailand, SE Asia
29-43 Portland, OR, USA urban/suburban (travel- Europe, South America
travel
war
travel

PE

CANADIAN

0-6.5 Vancouver, BC, Canada

6.5-10.5 Peshwar, Pakistan

urban/suburban rural

10.5-15 Lahore, Pakistan

15-15.5 Rogue River,OR, USA

15.5-18 Lahore, Pakistan

18-25 Canada

25-29 Portland, OR, USA

29-30 Pakistan, India, Nepal, Sri Lanka

30-35 Portland, OR, USA

urban/suburban

35.5- (Presently sold house \& is

embarking upon extended

sojourn to India, Nepal, Pakistan)

LH

FRENCH/

JAPANESEAMERICAN

Quito, Ecuador

4-5

Recife, Brazil

$5-7$

Rio de Janiero, Brazil

8-12 Woodbridge, VA, USA travel 
SP

PHILLIPINE/

AMERICAN

$\begin{array}{llc}0-1 & \text { Algiers, Algeria } & \text { urban/suburban } \\ 1-7 & \text { Alerandria, VA, USA } & \\ 7-8 & \text { Kano, Nigeria } & \text { international compound } \\ 8-8.5 & \text { San Jose, CA, USA } & \text { urban/suburban } \\ 8.5-10.5 & \text { Santa Cruz, Bolivia } & \text { rural farm } \\ 10.5-13 & \text { La Paz, Bolivia } & \text { urban/suburban } \\ 13-18 & \text { Kinshasa, Zaire } & \text { international compound } \\ 18-21 & \text { Portland, OR, USA } & \text { college }\end{array}$

PL

ANGLO-AMERICAN

0-2

2-3

Frankfurt, Germany

urban/suburban

3-3.5

Athens, Greece

$3.5-5$

Illinois, USA

military base

Taipei, Taiwan

$5-5.5$

South Carolina, USA

urban/suburban

5.5-8

Madrid, Spain

military base

9-12

Missouri, USA

Minnesota, USA

urban/suburban

Grafenwohr, Germany

12-17 Nurenberg, Germany

military base

17-37

Portland, OR, USA

urban/suburban

MJ

ANGLO-AMERICAN

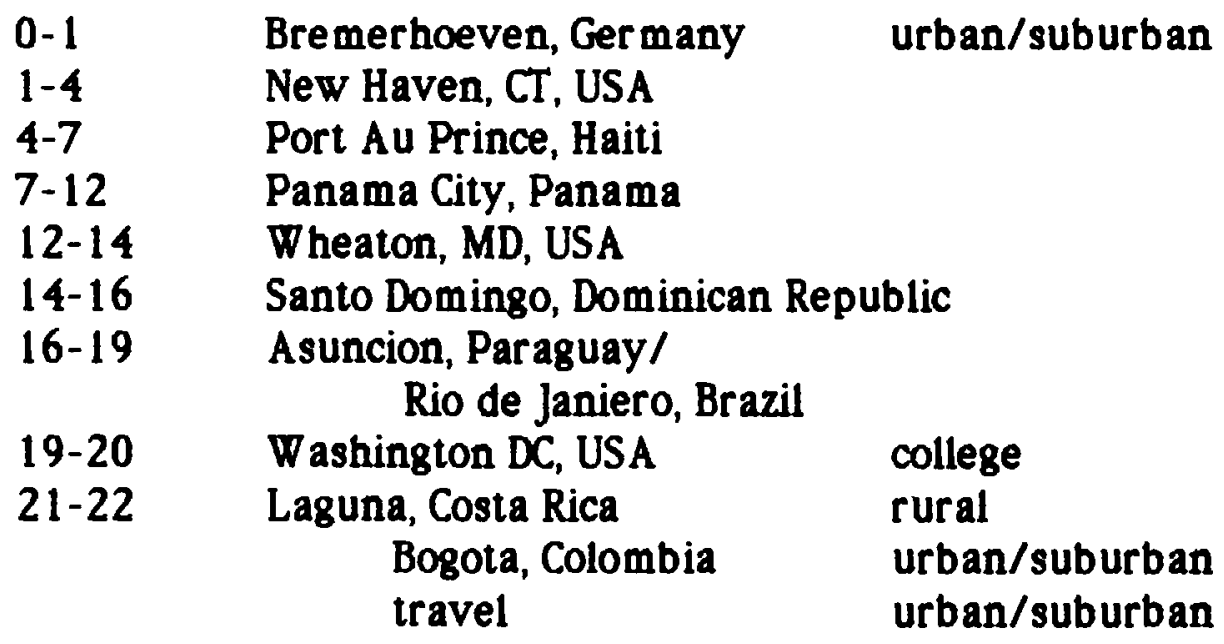


22-25 Olympia,WA, USA

Aberdeen, WA

25-26 Sublimity, OR, USA rural

26-34 Centerville, WA rural farm

34-35 Portland, OR / urban/suburban

Costa Rica travel

Dominican Republic

BW

ANGLO-AMERICAN

$0-1$

$1-2$

Portland, OR, USA

urban/suburban

2-3

3-5

5-6

6-7

MCMinnville, OR, USA

San Francisco, CA, USA

New York City, NY, USA

Los Angeles, CA. USA

San Francisco, CA, USA

New York City, NY, USA

Dallas, TX, USA

7-13 Tehran, Iran

13-28 Vientien, Laos

Scotland

28-36 Portland, OR, USA 


\section{APPENDIX D \\ INTERVIEW SCHEDULE OF QUESTIONS}

If there's anything you feel is unclear, tell me so I can clarify it for you, or if a question feels too probing. please let me knov.

\section{MULTICULTURAL ENCULTURATION}

1. What languages did you speak as you were growing up?

2. What level of proficiency did you achieve in these languages?

3. What languages do you speak now?

4. What do you think of most when you remember living in country $X$................., country $Y$ country $z$ ?

5 . Is there anything you especially miss about living in $?$

6. What, if anything, do you think you'd most appreciate or look for if you could return to country $\mathrm{X}$. country $Y$. country z. now? Describe.

7. Did you have a close relationship with anyone outside of your own native cultural group?

8. With whom did you identify or feel that you were the most like when you were in country $X$........., country $Y$ country $z$...........?

\section{MULTICULTURAL TRANSITIONS AND IDENTIFICATIONS}

9. If you could live anywhere you chose, where would it be? Why?

10. Have you ever felt surprised or confused by being excluded from a group you identified with or felt a part of? Please describe this experience.
A. Do you remember making efforts to become a part of the group?
B. Why did you choose this action? 
11. To what extent do you feel you are a part of each culture you've lived in?

12. When you think of people you know whose ethnic or national heritage is similar to your parents', do you feel a sense of belonging and identification?

13. How much do you feel a sense of belonging or identification with the people in these groups?

work colleagues

acquaintances

close friends

family

14. How do you think the people in each of these groups would describe your position in the $m$ ? (Belonging, identification, shared values,beliefs)

15. In what specific ways do you think living in different countries has influenced the person you are now?

16. Describe how you felt each time you found that you were moving to another country.

17. Was there an experience during early childhood or adolescence when you became aware of differences between yourself and your friends from another society or segment of society?
A. Was it a sudden or gradual awareness?
B. Did you feel any pain as a result of this awareness?
C. Describe.
D. Does this still bother you?

18. Do you see yourself as frequently undergoing personal transitions? If so, in what ways?

19. How do you usually react to unexpected changes in your life?

20. What, if any, occupational transitions have you made in the past decade?

21. Do you think your personal outlook on the world has undergone any major changes recently?

22. Do you see yourself as remaining stable and consistent in your beliefs and attitudes no matter what country you are in or what people you're with? 


\section{. MULTICULTURAL PERSPECTIVES}

23. In what ways do you think your cross cultural experiences have affected the way you perceive people from other cultures now?

24. Are there any political positions you feel are absolutely correct? Please explain.

25. Do you tend to be perceived as a confidant by people who know you? Why do you think this?

26. Do you think all of your friends have alot in common? Would they enjoy being with one another?

27. Do you enjoy getting together with all your friends at once or do you prefer keeping each part of your social life separate? Why?

28. What kinds of difficulties do you experience in decision making ?

29. When you're faced with a moral or ethical issue, how do you decide what is right or wrong for you?

30. In what ways do you think your international experiences have affected your values and ways of looking at the world?

31. Does your own world view include values from a variety of cultures?

32. Which, if any, value system, religion, or philosophy, do you believe would be the best for the whole world to follow? Why?

\section{MULTICULTURAL STRESSES}

33. What do you feel are the greatest disadvantages of growing up in several international environments?

34. What are the worst feelings you have about growing up in different countries?

35. Do you ever feel caught between conflicting sets of values?

36. Do you ever feel a sense of identity confusion? If so, in what ways?

37. How would you describe your relationships to other people? 
Do you see yourself as detached and aloof from most other people? Or, are you more attached and intimately involved?

38. Have you ever experienced "culture shock"?

39. Have you had the experience of "reentry shock"?

40. Do you ever feel overwhelmed by various demands that all seem equally valid?

\section{MULTICULTURAL MEDIATION TENDENCIES}

43. Are there any special skills or talents that you feel you've developed as a result of being brought up in different countries?

44. How do you respond when you're in the presence of people who are arguing or having a discussion that may lead to conflict, and you recognize that neither one understands what the other is saying?

45. Are you ever involved in problem solving situations between people from different cultural groups?

Please describe one such situation and your involvement.

46. What do you think is the best way to go about solving problems among individuals from different cultures?

47. In what ways do you think your cross cultural experiences have affected your career choices and directions?

\section{Other}

48. What do you think are the most important things you've learned through your international experiences?

49. Is there anything else about your life experiences in multiple countries that you would like to share at this time? 


\section{APPENDIX E \\ REFINED LIST OF THEMES}

\section{Multicultural Enculturation}

Demographic Screening instrument and Questions 1-8

\section{Demographic Enculturation Processes}

Primary Familiogenic Multiculturalism Type 1 and Type II

Secondary Idiogenic Multiculturalism

Theoretical Enculturation Processes

1) Foundations of cultural identity shaken

Psychoculturally diverse sense of awareness

Inability to identify with one cultural reality

2) Partial assimilation of cultures

3) Crisis of discovering cultural differences

Inner conflict due to identification with each cultural group

Inner conflict due to inability to identify with one cultural reality

\section{Multicultural Transitions and Identifications;}

(Questions 9-14, and 16-21).

4) International reference group

5) Frequent personal transitions

Need for growth and change

6) Contertual adaptability

7) Maintenence of inner stability through

contertual changes

Cyclic pattern of personality development

Repeated disintegration and reintegration of the psyche

Implicit growth, higher levels of integration each time

Evolutionary beings

\section{Multicultural Perspectives;}

(Questions 11,15 and 22-32)

8) Internationalism/Worldmindedness 
9) Cultural relativism

10) Non-judgementalness

11) Globalist, universalist perspective

Commitment to fundamental unity

Commitment to both similarities and differences

\section{Multicultural Stresses;}

(Questions 9,10,11,13,14,18,19,21,28,29,33-40)

12) Lack of belonging

Exists on margins of cultures and groups, partly in, partly out

Pain is in attempt to identify and belong

Unfulfilled belonging needs result in loss of objectivity

13) Identity issues

14) Detachment, aloof ness and indifference

Vulnerability and stress

Psychological identification without acceptance

"Dilletantism"/"deracine cosmopolitan"

Superficiality

Avoidance of real human problems

Internal flexibility

Overwhelmed by conflicting interests and demands of others

Ercessively vulnerable to stimuli

\section{Multicultural Mediation Tendencies}

(Questions 15,22,28,29,30,41-45)

15) Take inter mediary roles

Ability to serve as bridge between cultures

Seek to establish and balance communication

Facilitate action, and understanding

Are translators and synthesizers

16) Future oriented, creative work

17) General pur pose to contribute to international understanding

Free from local prejudices and values

18) Adaptability

19) Language learning skills

20) Ability to recognize and communicate within different cultural orientations

Have knowledge of cultural roles and expectations

Ability to interact in unfamiliar cultures in a relazed manner Ability to shift frame of reference 
Interpret expressions, intentions, and perceptions of each group to the other

Ability to perceive and anticipate potential frustrations between

diverse cultural groups

Unique capacity for nearness and sympathetic understanding

Often perceived as confidants

Sympathetic objectivity

Other:

Culture Shock:

Part of identity formation

Minimal due to experience with cultural changes

New Themes:

Pain of awareness of discrepancies between "haves" and "have nots"

Disgust for waste, opulence

Desire not to develop cultural value of materialism

Re-entry as the greatest shock

Emphasis on pace of life

Sense and value of time 